\title{
APPLICATION OF WHEY PROTEIN-POLYSACCHARIDE COMPLEXES IN AERATED DAIRY GELS
}

A Thesis
presented to
the Faculty of the Graduate School
at the University of Missouri-Columbia
In Partial Fulfillment
of the Requirements for the Degree
Master of Science
EMILY O'CHIU

Dr. Bongkosh Vardhanabhuti, Thesis Supervisor

MAY 2014 
The undersigned, appointed by the dean of the Graduate School, have examined the thesis entitled

\section{APPLICATION OF WHEY PROTEIN-POLYSACCHARIDE \\ COMPLEXES IN AERATED DAIRY GELS}

presented by Emily O'Chiu,

a candidate for the degree of Master of Science,

and hereby certify that, in their opinion, it is worthy of acceptance.

Dr. Bongkosh Vardhanabhuti, Department of Food Science

Dr. Ingolf Gruen, Department of Food Science

Dr. Paul Speckman, Department of Statistics 


\section{ACKNOWLEDGEMENTS}

I would like to thank my advisor Dr. Bongkosh Vardhanabhuti for her constant encouragement and support throughout my studies and research at Mizzou. I've accomplished more than I ever thought possible. The completion of this thesis could not have happened without her excellent guidance and advice.

Additionally, I send my thanks to Dr. Ingolf Gruen and Dr. Paul Speckman for serving on my thesis committee. I appreciate the time you have taken to offer me your suggestions and advice. I thank Harold Huff and Gordon Ellison for their technical help, and Joanne Lewis and Starsha Ferguson for their assistance throughout my graduate studies. Thank you also Lada Micheas and Yueli Sui of the Social Science Statistics Center for their assistance with data analysis. Within my lab, I owe so much to my fellow students, Yue He, Yan Huan, Sara Spoede, Parichart Thamnarathip, Zhengshan Wang, Jun $\mathrm{Xu}$, and Sha Zhang. Thank you all for your friendship and advice as we walk this path together.

Finally I am grateful for the love and understanding of my family, especially my husband Derek O'Chiu, my parents John and Cindy O’Keefe, and my sister Lauren Young. 


\section{TABLE OF CONTENTS}

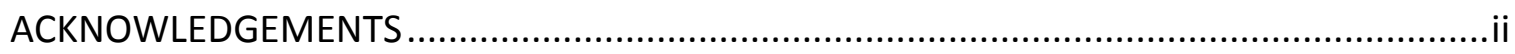

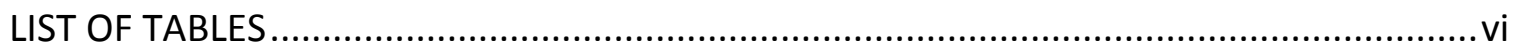

LIST OF FIGURES ..................................................................................................... vii

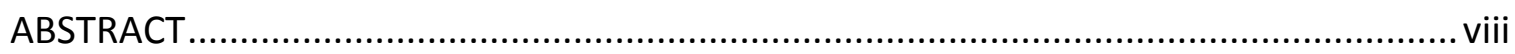

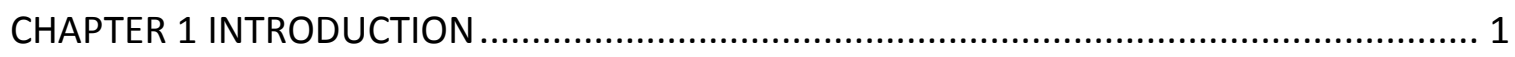

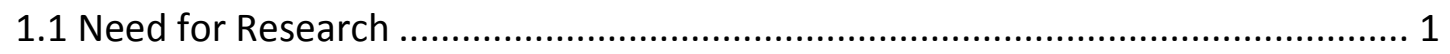

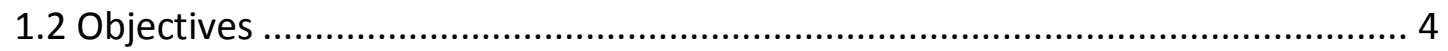

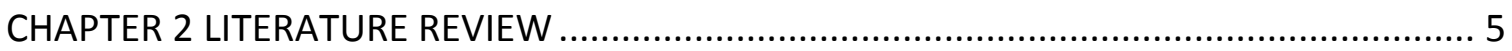

2.1 Foams and gels in the food industry ........................................................... 5

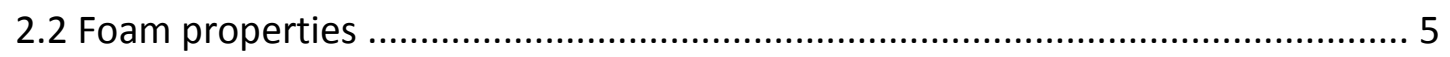

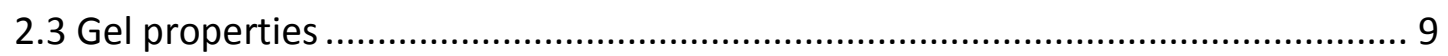

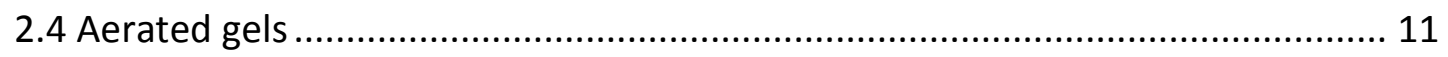

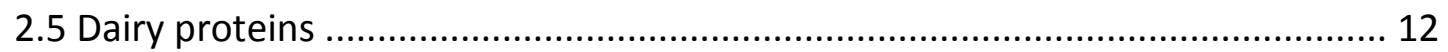

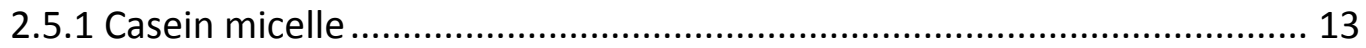

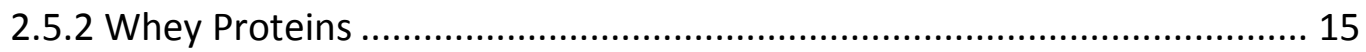

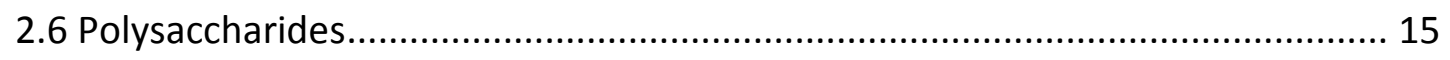

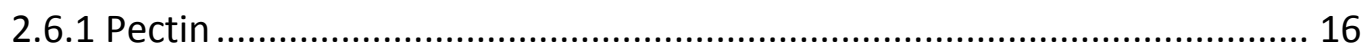

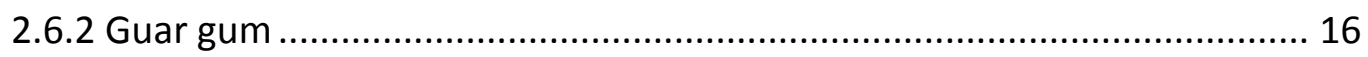

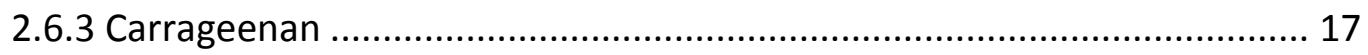

2.7 Protein polysaccharide interactions ................................................................ 19

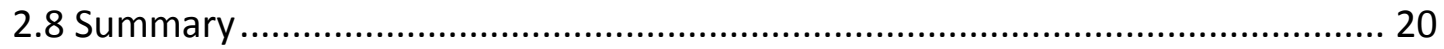

CHAPTER 3 MANUSCRIPT 1: PECTIN …………………............................................ 21

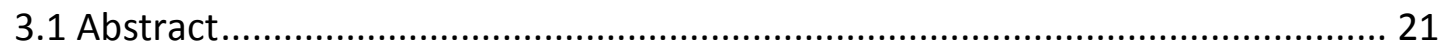

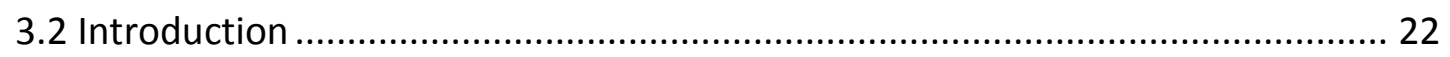

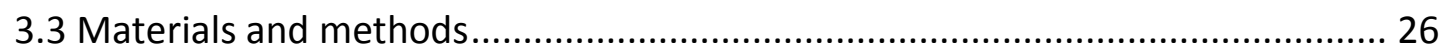




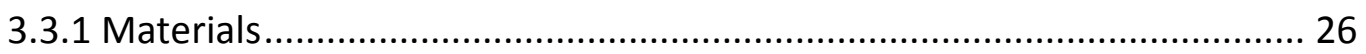

3.3.2 Stock Solution Preparation ................................................................ 26

3.3.3 Formation of Heated WPI-PS Complexes ............................................ 26

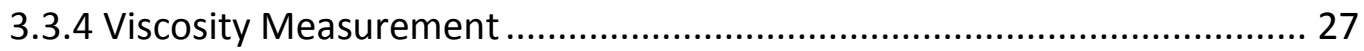

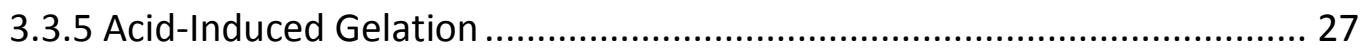

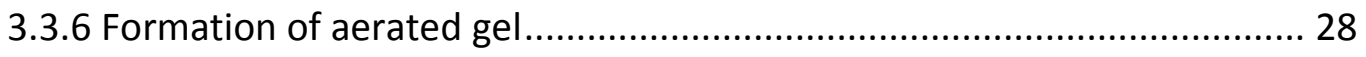

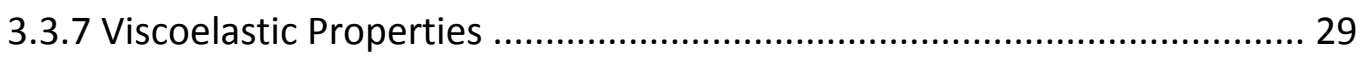

3.3.8 Lactic Acid Bacteria Gelation ............................................................. 30

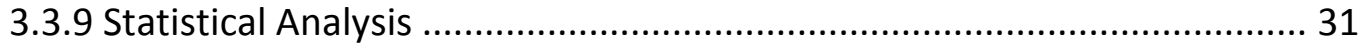

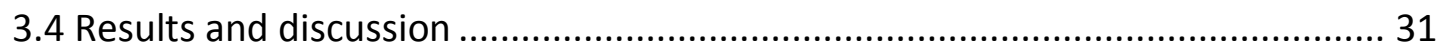

3.4.1 Aerated Gel Overrun ................................................................... 31

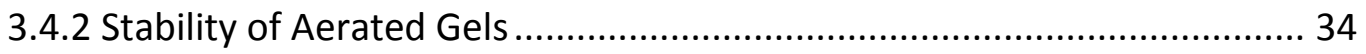

3.4.3 Water Holding Capacity ............................................................... 41

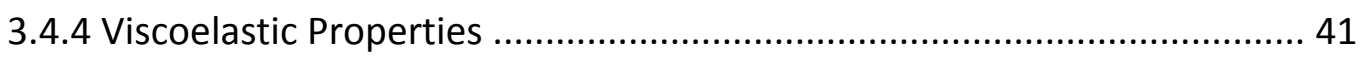

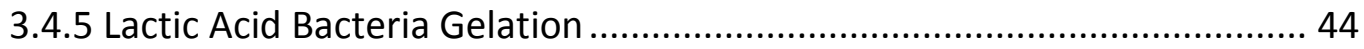

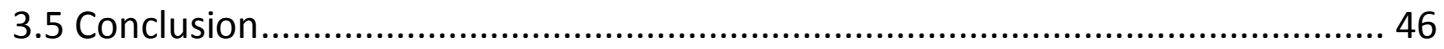

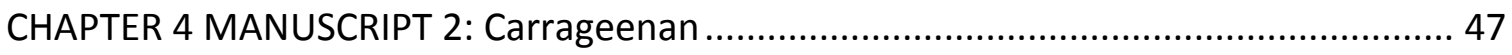

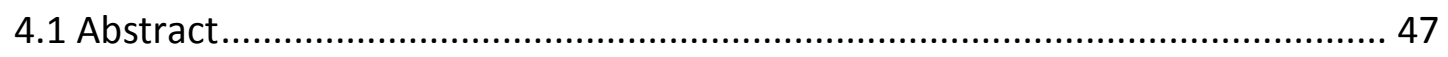

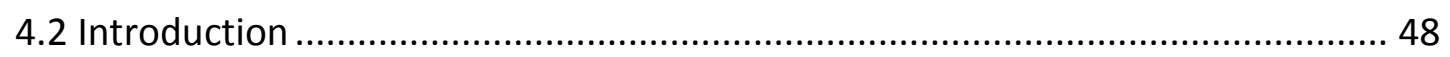

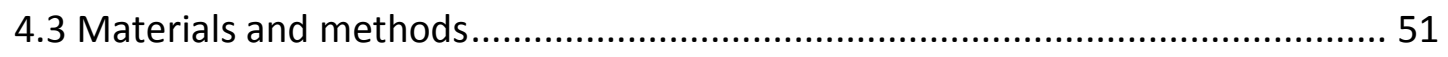

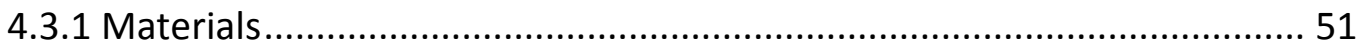

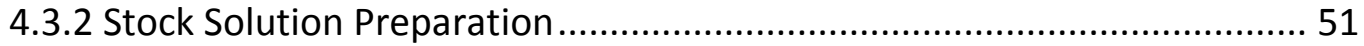

4.3.3 Formation of Heated WPI-PS Complexes ............................................ 52

4.3.4 Viscosity Measurement ................................................................ 52

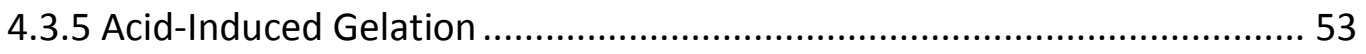

4.3.6 Formation of aerated gel.......................................................... 54 


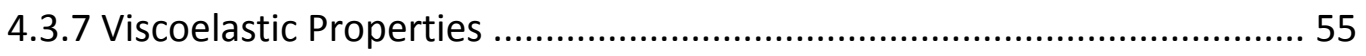

4.3.8 Lactic Acid Bacteria Gelation .................................................................. 55

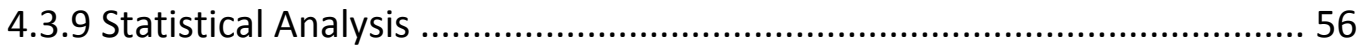

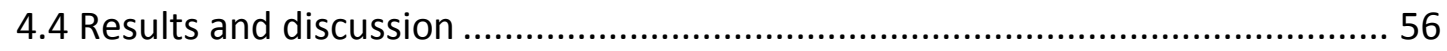

4.4.1 Aerated Gel Overrun ................................................................ 56

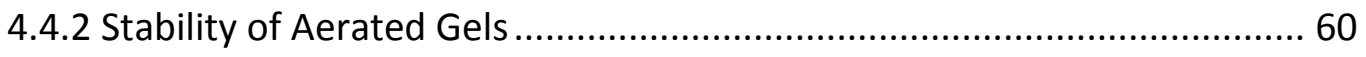

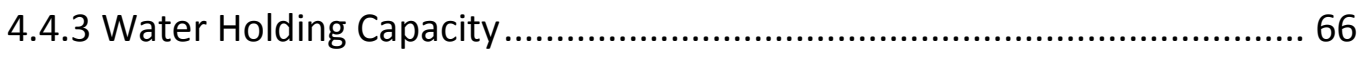

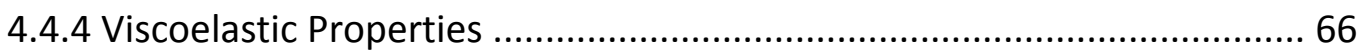

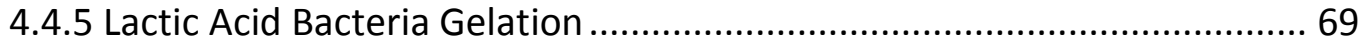

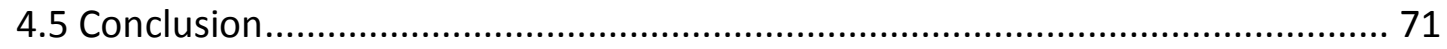

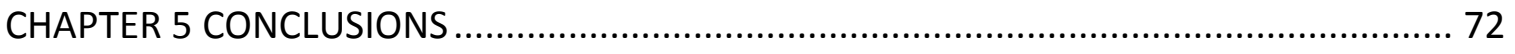

5.1 Concluding Statements on Aerated Gels .................................................. 72

5.2 Overall Benefit and Future Direction ........................................................ 72

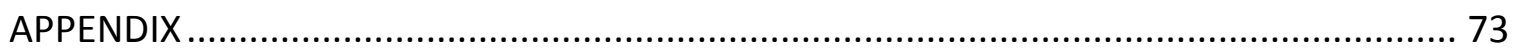

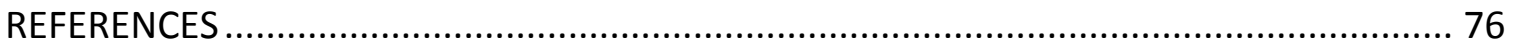




\section{LIST OF TABLES}

Table $\quad$ Page

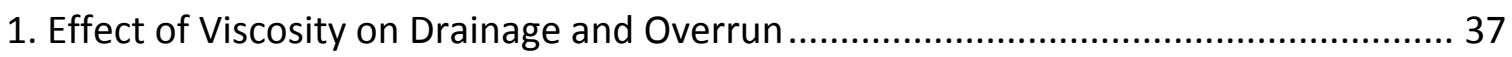

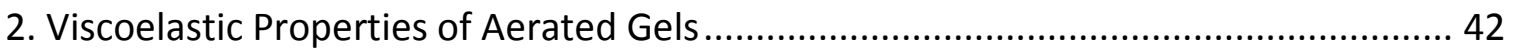

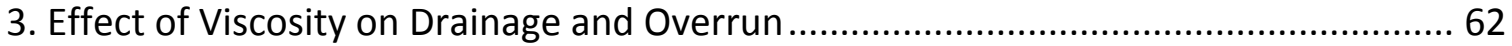

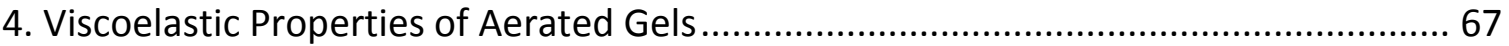

5. Additional data for measured aerated gel properties ........................................... 73 


\section{LIST OF FIGURES}

$\begin{array}{lll}\text { Figure } & \text { Page }\end{array}$

1. Diagram of hairy casein micelle structure (Holt and Horne 1996) ........................... 14

2. Carrageenan coil formation (Gulrez and Al-Assaf 2011) ...................................... 18

3. Percent overrun of aerated gels with different polysaccharide concentrations ......... 33

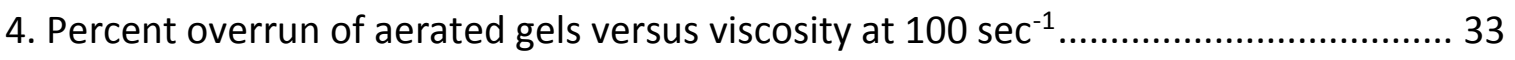

5. Percent drainage of aerated gels with different polysaccharide concentrations ........ 36

6. Percent drainage of aerated gel versus polysaccharide viscosity at $8 \mathrm{sec}^{-1} \ldots \ldots \ldots \ldots \ldots \ldots . . . . . .40$

7. Percent drainage of aerated gel versus SMP-complex viscosity at $8 \sec ^{-1} \ldots \ldots \ldots \ldots \ldots . . . . . . . .40$

8. Percent drainage of the aerated gels with two acidulation methods ....................... 45

9. Percent overrun of aerated gels with different polysaccharide concentrations ........ 59

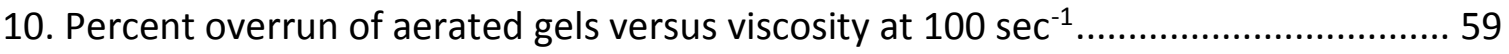

11. Percent drainage of aerated gels with different polysaccharide concentrations ...... 62

12. Percent drainage of aerated gel versus polysaccharide viscosity at $8 \mathrm{sec}^{-1} \ldots \ldots \ldots \ldots . . . .65$

13. Percent drainage of aerated gel versus SMP-complex viscosity at $8 \mathrm{sec}^{-1} \ldots \ldots \ldots \ldots \ldots . . . . . .65$

14. Percent drainage of the aerated gels with two acidulation methods ...................... 70

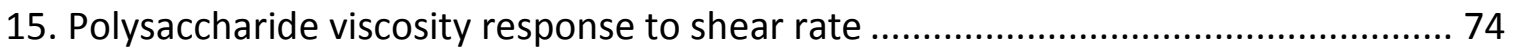

16. SMP-Complex mixture viscosity response to shear rate ....................................... 75 


\title{
APPLICATION OF WHEY PROTEIN-POLYSACCHARIDE COMPLEXES IN AERATED DAIRY GELS
}

\author{
Emily O’Chiu
}

Dr. Bongkosh Vardhanabhuti, Thesis Supervisor

\begin{abstract}
Previous research has shown that heated soluble complexes of whey protein isolate (WPI) with polysaccharides can improve both foam stability and acid-induced gel strength. We utilized these complexes in aerated dairy gels, which could be formulated into novel-textured high-protein desserts. Two families of polysaccharides having different degrees of charge density were chosen. The first included: low methoxyl pectin (high charge), high methoxyl type D pectin (low charge), and guar gum (neutral charge). The second had three carrageenans, $\lambda$ - (high charge), $\mathrm{l}$ - (medium charge), and $\mathrm{k}$ - (low charge). WPI-polysaccharide complexes were prepared by heating the mixed solutions ( $8 \%$ protein, 0 to $1 \%$ polysaccharide) at $\mathrm{pH} 7$ and then mixing with heated skim milk powder ( $8 \%$ protein). To form aerated gels, $2 \%$ glucono- $\delta$-lactone (GDL) was added and foam was generated by whipping with a handheld frother. The foam set into a gel as the GDL acidified to a final pH of 4.2. The aerated gels were evaluated for stability, overrun, and rheological properties.
\end{abstract}

Overall stability was indicated by measuring liquid separation drained from the foam before it set as a gel. Rheological results showed no significant difference in 
gelation time among samples; therefore, stronger interactions between WPI and high charge density polysaccharide were likely responsible for increased stability. In most cases overrun of aerated gels significantly decreased as polysaccharide concentration increased due to increased viscosity which limited air incorporation. However in some cases of high charge carrageenans, overrun increased as concentration increased, related to stronger interfacial films overcoming the effect of viscosity. Yield stress and $\mathrm{G}^{\prime}$ are important rheological indicators of firmness and mouthfeel and are increased with increasing polysaccharide charge density. For both the pectin and carrageenan systems, it was found that yield stress and $\mathrm{G}^{\prime}$ could be predicted using a multiple regression model using gel strength of non-aerated gel and the aerated overrun.

Stable dairy aerated gels can be created from WPI-polysaccharide complexes. High charge density polysaccharides, at concentrations that provide adequate viscosity, are needed to achieve stability while also maintaining solution overrun capabilities. Knowledge gained from this study can be used by food manufacturers to formulate dairy-based aerated gel foods set by acid or calcium such as whipped yogurts and mousses. 


\section{CHAPTER 1 INTRODUCTION}

\subsection{Need for Research}

As a byproduct of cheese manufacturing, whey protein can be an economic and environmental burden when unused. Alternatively, its high biological value protein content and unique properties make it a promising food ingredient (Smithers 2008). Whey protein is commonly added to dairy foods such as yogurt, ice cream, and cheese to increase total protein content, alter textures, or replace more costly ingredients (Singleton 1973; Kinsella and Whitehead 1989; Sodini and others 2005). Understanding whey protein functional properties that allow it to support different food textures is crucial to expanding its use to new applications in the food industry.

There is opportunity to expand the use of whey protein in nutritionally focused products. As consumers look for more healthful food choices there is interest in foods that are more filling with less calories. Putting whey protein into an aerated system can address consumer's desire to lower calorie intake in two ways. Proteins as a class are more satiating than carbohydrates or fat and whey protein may suppress gastrointestinal hormones to further improve satiation. (Hall and others 2003; Veldhorst and others 2009). Additionally, adding bubbles to snack foods such as chocolate or cheese puffs introduces a novelty factor (Campbell and Mougeot 1999) and has been shown to decrease energy intake by increasing the total food volume per calorie (Osterholt and others 2007). Although whey protein foaming and gelation properties are well understood, little research has been done on aerated whey protein gels. 
There is a long history of aerating foods through several methods including; fermentation, whipping, gas injection, or frying. Many aerated foods such as soufflés, ice cream, and whipped cream rely on fat molecules to support the aerated network (Campbell and Mougeot 1999; Allen and others 2006). In a nutritionally focused product, fat content may be undesirable, so additional stabilization mechanisms are needed. The functional properties of whey protein can be exploited to prevent system destabilization such as drainage, coalescence, or disproportionation.

In a foam system, stability can come from increased solution viscosity, increased interfacial elasticity, or control of bubble size. The amphiphilic nature of whey protein allows it to interact with both the air and water phase of the foam interface. Native whey proteins are able to adhere quickly to the interface to increase stability during the foaming process. When heated, the whey proteins form aggregates or polymers, resulting in slower interfacial adsorption due to their larger size. However, they are better able to stabilize the foam by increasing the interfacial elasticity which increases resistance to deformation forces (Davis and Foegeding 2004; Schmitt and Turgeon 2011). The introduction of polysaccharides into the foam solution can work in conjunction with either native whey protein or whey protein polymers to further stabilize the foam. Polysaccharides increase the solution viscosity which contributes to foam stability, however their electrostatic charge also plays an important role. By interacting with oppositely charged regions on the protein the polysaccharide can modify its function at the interface within a range of $\mathrm{pH}$ (Schmitt and Turgeon 2011). 
Further research on the relationship of whey protein and polysaccharides focuses on their properties when co-heated as a complex. Typically in a mixed system with two charged polymers such as whey proteins and polysaccharides, they will either segregate into a bilayer system, or attract and form insoluble aggregates (de Kruif and Tuinier 2001). However, when solutions of native whey protein and polysaccharides are heated together at a $\mathrm{pH}$ above the protein isoelectric point ( $\mathrm{pl}$ ), the positive patches of the protein that are exposed during unfolding are able to interact with the negatively charged polysaccharides to form a heated soluble complex. A study of whey protein foam properties found that heating the whey protein with $\lambda$-carrageenan led to increased foamability and increased drainage $1 / 5$ life. These changes are attributed to protein-polysaccharide interactions improving elasticity and film viscosity of the foam (Wang 2013).

Whey protein-polysaccharide heated soluble complexes have also been applied to acid-induced gelation. When whey proteins in solution are subjected to gradually lowering $\mathrm{pH}$, the change in the net electric charge of the aggregates allows them to interact and form a gel network (Alting and others 2002). The addition of polysaccharides to the system can be used to alter gel properties and microstructure (Cavallieri and Cunha 2009). A number of polysaccharide chemical properties have an effect on the gel microstructure. Charge density has the largest effect, followed by molecular weight and chain stiffness (de Jong and van de Velde 2007). Recent works have shown that acid-induced gels formed from heated whey protein-polysaccharide complexes have improved water holding capacity and gel strength compared to those 
from whey protein polymers with added polysaccharides (Zhang and others 2014; Zhang and Vardhanabhuti 2014).

This study investigates whether heated whey protein-polysaccharide complexes can be applied to stabilize aerated whey protein gels by combining their properties in improving both foams and acid-induced gels. A greater understanding of how heated complex addition can be used to maintain product stability while manipulating properties, such as overrun and yield stress, will allow the dairy industry to create successful novel-textured products.

\subsection{Objectives}

The overall objective of this research was to investigate the effect of heated whey protein-polysaccharide complexes on low pH aerated skim milk gels. Several polysaccharides were used in the system to look at the roles charge density and polysaccharide concentration play on the stability of the aerated system during the acidinduced gelation process. Specific objectives were (i) to determine the effect heated whey protein-polysaccharide complexes on the stability and physical properties of low $\mathrm{pH}$ aerated gels, (ii) to determine the key factors that affect the stability and properties

of low pH aerated gels, (iii) to apply low $\mathrm{pH}$ aerated gels in creating whipped yogurt. 


\section{CHAPTER 2 LITERATURE REVIEW}

\subsection{Foams and gels in the food industry}

Throughout history, foams and gels have been used in food to create unique sensory experiences. Common foods containing foams or gels include ice cream, yogurt, gelatin, pudding, soufflé, merengue, and bread. Many processes are available to create and modify foams or gels with foods. Gels can be made through either heating or fermenting proteins or sugars. They historically have been used as a means of preservation (Tamime and others 2001). Foaming, the containment of air bubbles within a food, can be achieved by whipping, gas injection, steam generation, or fermentation (Campbell and Mougeot 1999).

Careful control of the textural characteristics of the foam or gel is necessary for a product to be acceptable. Ice cream, for example, is too firm if no air is incorporated. However, with too much air the ice cream may seem insubstantial and will melt quickly. If the gel of a yogurt is too weak, then it may release liquid during storage; if it is too strong, then the yogurt may seem dense or chewy. In the cases of ice creams and yogurts, protein plays a pivotal role in controlling the desired characteristics (Sodini and others 2005; Patel and others 2006). Before learning how proteins can improve the foam and gel properties of food, first it is important to review their respective physical structures.

\subsection{Foam properties}

A foam can be defined as a combined system of a dispersed phase (gas) within a continuous phase (liquid or solid). The air cells from a foam are crucial to the final 
textural characteristics of foods such as beer, bread, ice cream, and marshmallows. The air cells present within the structure reduce the density, change the texture to impart a smooth or creamy mouthfeel, modify the digestibility, and alter the flavor release (Campbell and Mougeot 1999; Lau and Dickinson 2005).

The processes used to generate foam can be divided into four categories: agitation, injection, steam generation, and fermentation. Agitation involves whipping, shaking, or frothing a liquid solution. The high level of shear force acting on the viscous liquid entraps more and more air bubbles until it becomes a viscoelastic solid. As the process continues the bubble distribution becomes more uniform in size and shape (Allen and others 2006). Foam generated through air injection is most often seen with $\mathrm{CO}_{2}$ addition to carbonated beverages. Steam generation is common in grain products such as popcorn, puffed cereal, and fried dough. Through rapid heating, either dry or in hot oil, the water in these products becomes steam which generates a pocket of air. The heating simultaneously solidifies the surrounding material so the air is not able to escape. The final method of foam generation is fermentation in which microorganisms such as yeast produce $\mathrm{CO}_{2}$ gas within the product (Campbell and Mougeot 1999).

Foam instability can be divided into three categories: drainage, coalescence, and disproportionation. Drainage is the result of gravitational forces and the density difference between the air cells and their surrounding medium. The bubbles gather at the top of the solution, while the liquid between them flows to the bottom. Coalescence can be defined as the rupture of the film interface between two bubbles connecting them into one larger bubble. Disproportionation occurs when the dispersed gas phase 
migrates through the continuous phase from the smaller bubbles to the larger ones due to a difference in pressure. Together, coalescence and disproportionation result in altered bubble size dispersion over time that favors larger bubbles in a process known as foam coarsening (Lau and Dickinson 2005; Blijdenstein and others 2010). Foam instability leads to textural defects and is the cause of the short shelf life for many aerated foods.

It is possible to add ingredients that will improve the foam stability of a food. A resolution for drainage defects would be to increase solution viscosity. A more viscous continuous phase will limit the ability of the bubbles to migrate upwards (Davis and Foegeding 2004; Lau and Dickinson 2005). Surfactants are used to address coalescence and disproportionation. A surfactant is a molecule that is active at the interface between the dispersed and continuous phase. The surfactant characteristics that relate to high surface activity include; adequate size and flexibility to have many contact points at the interface, readiness to unfold, and possession of both hydrophobic and hydrophilic regions (Kokini and Aken 2006; Jimenez-Junca and others 2011). The foaming performance of a surfactant can be characterized by foam capacity, the initial maximum volume, and foam stability, the degradation in volume over time (Raymundo and others 1998). A maximally stable foamed food will have relatively large, uniform air bubbles entrapped in a gelled or solid continuous phase (Kokini and Aken 2006).

Foam capacity is typically indicated by the measurement of overrun which is commonly expressed as the percent change in volume after aeration. Due to the complex nature of simultaneous air entrapment and dis-entrapment during foaming, 
overrun is effected not only by the surfactant present but also the speed, temperature and $\mathrm{pH}$ of the solution (Campbell and Mougeot 1999; Luck and others 2002). In dairy foods, overrun can be as low as $15 \%$ in premium ice cream and as high as $120 \%$ in whipped cream topping (Kammesheidt 2003).

Foam stability is typically indicated by drainage. The dynamic nature of a foam system is inherently unstable in which drainage begins immediately after aeration ends. Drainage can only be fully stopped if the continuous phase of the foam solidifies enough to resist gravitational flow. The difference in a 'stable' versus 'unstable' foam is whether the time scale for drainage is longer or shorter than the needed shelf life. For example, coffee drinks containing foam need to be consumed immediately after preparation, while foamed marshmallows can be packaged and stored for several years with no appreciable instability (Lau and Dickinson 2005; Jimenez-Junca and others 2011).

While both overrun and drainage are useful measurements for comparing two foams, they do not necessarily express mouthfeel characteristics of foams when consumed. A third important foam property is yield stress, a measure of foam elasticity and how it begins to flow under increasing shear forces. Vane rheometry is often used to exert sideways force within a foam to detect the point at which it stops resisting like a viscoelastic solid and starts flowing like a liquid. High yield stress is related to increased firmness and decreased spreadability (Pernell and others 2000; Davis and Foegeding 2004; Thakur and others 2008). 


\subsection{Gel properties}

A gel can be defined as a liquid (dispersed phase) that is trapped in a smaller proportion of solids (continuous phase) arranged in a three dimensional network. In food gels such as gelatin, boiled eggs, and yogurt, the solids responsible for gelation are proteins. Food gels can be evaluated by measuring the physical properties that alter their mouthfeel when consumed such as compression strength, water holding capacity, and viscoelastic storage modulus (G') (Schmidt and Morris 1984; Foegeding and others 2002). The compression strength can be related to the feeling of a gel being broken between the teeth and the pieces formed by chewing. Water holding capacity is a measure of how well the water stays within the gel network. It is an important measure of both gel mouthfeel and storage stability. The viscoelastic property $\mathrm{G}^{\prime}$ is a measure of gel deformation under shear forces and relates to gel oral viscosity and mouth coating sensations (Foegeding 2006; Lee and Lucey 2006).

Protein gelation is divided into two mechanisms: heat induced and cold gelation. Adequate protein concentration is crucial for successful heat induced gelation. The proteins in the solution denature in response to heat and form cross links through protein-protein interactions. If they are at a concentration above the critical gelation point, then the crosslinking will be able to form a water holding gel network (Foegeding 2006). The proteins in heat induced gel networks are either particulate or fine stranded. The distinction between the two types is controlled by $\mathrm{pH}$ and ion concentration. The proteins in a particulate gel are gathered in large irregularly shaped aggregates. The aggregates form by rapid interactions between the proteins as they are heated under 
conditions where they are weakly charged ( $\mathrm{pH}$ near $\mathrm{pl}$ ) or in the presence of high ion concentration. Textural qualities of particulate gels include fracturing easily under compression and having poor water holding capacity, including the release of water when broken. A fine stranded gel network forms more slowly, under conditions of low ionic strength or when the proteins are strongly charged ( $\mathrm{pH}$ far from $\mathrm{pl}$ ). The proteins have more time to denature when heated and form a more elongated, organized protein network as they crosslink (Foegeding 2006; Vardhanabhuti and others 2010).

As seen in the example of particulate gels, both $\mathrm{pH}$ and ion concentration can alter the gelation properties of protein; this can be useful in forming gels at protein concentrations below the critical gelation point in a process known as cold gelation. Acid-induced gelation is a two-step process; first protein aggregates are formed at or near neutral $\mathrm{pH}$, and second the $\mathrm{pH}$ is lowered to form a gel. Globular proteins are not able to form a gel network until after they have been heated. The heating process denatures the proteins and causes them to form repelling aggregates in the solution. Next, an acidulation agent is added to the solution. As the $\mathrm{pH}$ lowers, the electrostatic charge of the protein decreases until the protein is near its pl. At that time, the proteins no longer repel each other and instead come together to form a cross-linked gel (Horne 1999; Vardhanabhuti 2000; Alting and others 2002). Lactic acid bacterial fermentation of milk to form yogurt or sour cream is an example of acid-induced gelation. Both the final $\mathrm{pH}$ and the rate of $\mathrm{pH}$ change have a significant effect on gel properties. For a gel with good strength and water holding properties, the $\mathrm{pH}$ must reduce from above the protein pl to well below it at a slow rate in order to allow time for an organized network 
to form (Jumah and others 2001). Cold gelation can also take place with the addition of ions instead of acidulation agents. Positively charged ions such as $\mathrm{Na}+$ or $\mathrm{Ca}++$ interact with the negatively charged proteins and, through the process of charge shielding, reduce the repelling forces between the proteins until they are able to cross link (Kuhn and others 2010; Tomczynska-Mleko 2013).

\subsection{Aerated gels}

One new area of development for the food industry is in aerated gels, defined as a three phase system of both gas and liquid entrapped in a solid network. Aerated gels share the properties of both foams and gels. Aeration of gels can include the creation of large bubbles that significantly alter the texture of a food, or micro-bubbles that are not perceptible but influence sensory characteristics. Much like a foam, they feel lighter and creamier and deliver flavor compounds at a different rate than their non-aerated counterparts. Aerated gels are created when a traditional foam goes through a solidification process of the continuous phase, or when a gas is pumped into a formed gel through engineered micro-channels or a porous membrane (Zúñiga and Aguilera 2008; Tiwari and Bhattacharya 2011). Alternatively, a gel can be agitated after formation to add air volume if the gel network will re-set after the disruption (TomczyŃSka-Mleko 2013).

Aerated gels in foods present interesting opportunities for nutritional benefits. The dietary practice of volumetrics is founded on the principle that people decide how much to eat by volume and that decreased energy intake can be achieved by increasing the total food volume per calorie (Osterholt and others 2007; Williams and others 
2013). By virtue of the incorporated air, a serving of an aerated gel will be lower in calories than a similar portion of non-aerated gel. If the bubbles are sufficiently small, then the change may be unnoticeable. This principle is already in use in low calorie chocolates and margarines, but these foods are emulsions and not gels (Haedelt and others 2007; Zúñiga and Aguilera 2008).

Subtle changes in texture can have an impact on the expected satiation effects of food. Foods that are creamier or have a thicker mouthfeel are linked to the expectation of being full longer (McCrickerd and others 2012). Traditionally, creaminess is caused by fat in food; however, aerated gels formed with WPC and inulin fiber were able to stabilize and replace a portion of fat in guava mousse with no change in sensory attributes (Buriti and others 2010). In addition to increasing satiety through texture, aerated gels are also able to improve satiety by their protein content. Proteins as a class impart higher satiety than carbohydrates or fat. In fact, there is evidence that certain proteins such as whey protein may suppress gastrointestinal hormones to further improve satiety. (Hall and others 2003; Veldhorst and others 2009). In addition to the nutritional benefits of any aerated gel, those containing dairy ingredients have additional qualities to offer. The calcium and protein specific to dairy foods have been linked to improved bone health, weight loss, and reduced risk of chronic disease (Heaney and Layman 2008; Korhonen 2009; Rice and others 2013).

\subsection{Dairy proteins}

As a solution, milk can be characterized as an aqueous dispersion of casein micelles (2.8\%) with a smaller amount of whey protein $(0.6 \%)$, lactose $(4.8 \%)$, and 
minerals (0.7\%) (de Bont and others 2002; McMahon and others 2009; Dalgleish 2011). The two protein categories in dairy foods each have unique functional properties and contribute to the diverse final structure of foods such as ice cream, yogurt, sour cream, cheese, and whipped topping.

\subsubsection{Casein micelle}

Nearly $80 \%$ of the protein in milk is casein, all of which is found in micelles.

Casein micelles are stable, protein-based, colloidal structures that average $200 \mathrm{~nm}$ in diameter (Dalgleish 2011). They are comprised of $\alpha_{\mathrm{s} 1}$-casein $\alpha_{\mathrm{s} 2}$-casein, $\beta$-casein, $\mathrm{k}$ casein, and calcium phosphate (McMahon and others 2009; Dalgleish 2011). A-casein and $\beta$-casein are rich in phosphoseryl groups that allow them to aggregate and participate in calcium bridges in the center of the casein micelle, and k-casein is a surface active glycoprotein with 3-4 glycosidic chains attached to its protein backbone (McMahon and others 2009; Dalgleish 2011; Ettelaie and others 2014). The amphiphilic nature of $\mathrm{k}$-casein allows it to arrange itself on the surface of the micelle in brush-like layers shielding the more hydrophobic caseins from the aqueous environment (Figure 1). This heterogeneous surface gives casein micelles steric stability and multiple contact points with other compounds in the solution (Holt and Horne 1996; Ettelaie and others 2014). 


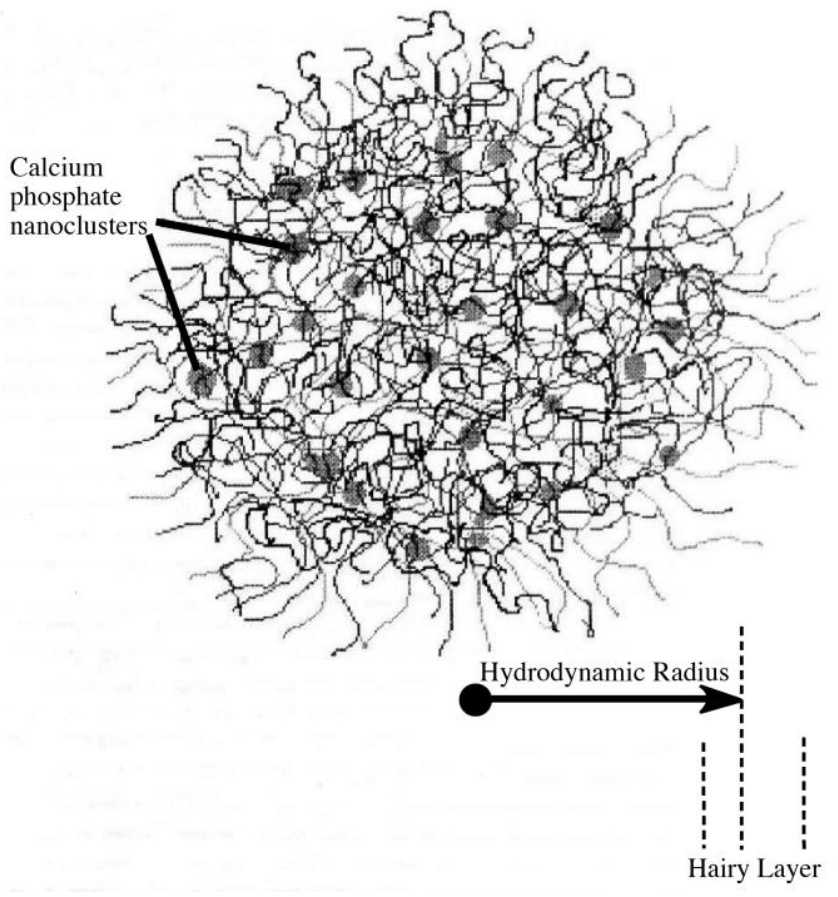

Figure 1 Diagram of hairy casein micelle structure (Holt and Horne 1996)

Either decreasing $\mathrm{pH}$ during acidification or an increasing ion concentration will change the conformation of the casein micelle, both interior and surface, and its relationship to other compounds (McMahon and others 2009). The calcium phosphate within the micelle becomes more soluble while simultaneously the electrostatic repulsion between caseins decreases as they approach pl. The dissociated proteins create loosely formed non-spherical aggregates and smaller micelles that maintain $\mathrm{K}$ casein coverage at the surface. Because it lacks the electrostatic force necessary to maintain the hairy surface formation, the $\mathrm{k}$-casein is flattened. This allows the proteins to come closer together and to form soluble aggregates or a gel network (Del Angel and Dalgleish 2006; McMahon and others 2009; Dalgleish and Corredig 2012). 


\subsubsection{Whey Proteins}

Whey proteins comprise $20 \%$ of the total protein in milk and are a mixture of $\beta$ lactoglobulin, $\alpha$-lactalbumin, immunoglobulin, bovine serum albumin, and lactoferrin (Tosi and others 2007; Donato and Guyomarc'h 2009). Whey is produced in excess during cheese production, but it has value as a food additive to improve protein content and texture of other dairy foods such as ice cream, yogurt, and nutritional beverages (Singleton 1973; Smithers 2008). Whey proteins' wide array of functional properties allow them to be used in products with a variety of textures. Due to their size, ease in unfolding, and amphiphilic nature, whey proteins are capable of stabilizing foams, emulsions, and gels. When heated, the proteins denature and polymerize to form large aggregates in which they then have higher levels of cross linking and protein-protein interactions including synergistic interactions when mixed with $\mathrm{k}$-casein. This leads to strengthened gels and improved stability of emulsions and foams (Bikker and others 2000; Vardhanabhuti 2000; Foegeding and others 2002; Tosi and others 2007; Donato and Guyomarc'h 2009).

\subsection{Polysaccharides}

The common polysaccharides of pectin, guar gum, and carrageenan are often included in the production of dairy foods such as flavored milk beverages, cheese, yogurt, and ice cream to control their viscosity, mouthfeel, and texture (de Kruif and Tuinier 2001; de Bont and others 2002). The effect of the polysaccharide on the final product properties is influenced by characteristics such as molecular weight, chain stiffness, and electrostatic charge (de Jong and van de Velde 2007). 


\subsubsection{Pectin}

Pectin is an anioinic polysaccharide whose functionality is controlled by the amount of carboxyl groups that have been esterified by methoxyl. Low methoxyl (LM) pectin is a form of the polymer that has a higher degree of esterification and thus a stronger negative charge; high methoxyl (HM) pectin has a weaker negative charge (Matia-Merino and Singh 2007).

At neutral $\mathrm{pH}$ both $\mathrm{LM}$ and $\mathrm{HM}$ pectin do not interact with casein micelles or whey protein. As the $\mathrm{pH}$ lowers, electrostatic-based absorption occurs at about $\mathrm{pH} 5.3$ for casein and $\mathrm{pH} 4.2$ for whey protein, below which the protein will have a positive charge to interact with the negatively charged pectins. The charge density of the pectin will control the absorption rate of the pectin to the protein surface by changing the pectin conformation. The amount of pectin necessary for full surface coverage is less for HM pectin than it is for LM pectin. Pectin absorption can result in both electrostatic and steric stabilization of casein micelles and whey protein aggregates in solution. (Maroziene and de Kruif 2000).

\subsubsection{Guar gum}

Guar gum is classified as a galactomannan, a polysaccharide composed of a mannose backbone with galactose residue side chains. It is derived from plant seeds and is commonly used as a thickening agent. (Bourriot and others 1999b; de Kruif and Tuinier 2001; Thaiudom and Goff 2003). In solution, guar gum forms large, round particles that are neutrally charged. Their size and lack of electrostatic attraction prevents them from adhering to dairy proteins at any $\mathrm{pH}$. Osmotic pressure reactions 
push them away from the space between casein micelles or between whey protein aggregates causing visible phase separation. In some cases depletion flocculation causes the protein to form an aggregate network, in which some pockets of guar gum may be trapped (Bourriot and others 1999b).

\subsubsection{Carrageenan}

Carrageenans are often added to dairy desserts to improve particle suspension or as a thickening or gelling agent. They can be divided into three classes based on the number of sulfate groups per disaccharide, $\mathrm{k}$-carrageenan has one sulfate group, lcarrageenan has two, and $\lambda$-carrageenan has three. The number of sulfate groups controls how negatively charged the polysaccharide molecules are and effects their conformations differently under various temperature and ionic conditions (Bourriot and others 1999a; Langendorff and others 2000).

The most negatively charged carrageenan, $\lambda$-carrageenan, has a loose coil structure. It has been shown to adhere to casein micelles at $60^{\circ} \mathrm{C}$ when other carrageenans do not, due to electrostatic forces (Langendorff and others 2000). When present in a mixed solution that is heated to $80^{\circ} \mathrm{C}$ then cooled past the transition temperature of about $49^{\circ} \mathrm{C}$ the $\mathrm{k}$-carrageenan and $\mathrm{l}$-carrageenan will change from a coil structure to a tighter more organized helix structure (Figure 2). When they do so, the charge density is increased to a high level that allows for adherence of the carrageenan to the micelle surface. The transition temperature is effected by ions present in the solution, it increases when calcium or potassium ions are present. The presence of ions 
in solution as it cools can cause the forming helices to aggregate together to make a stronger gel network (Langendorff and others 2000; de Kruif and Tuinier 2001).

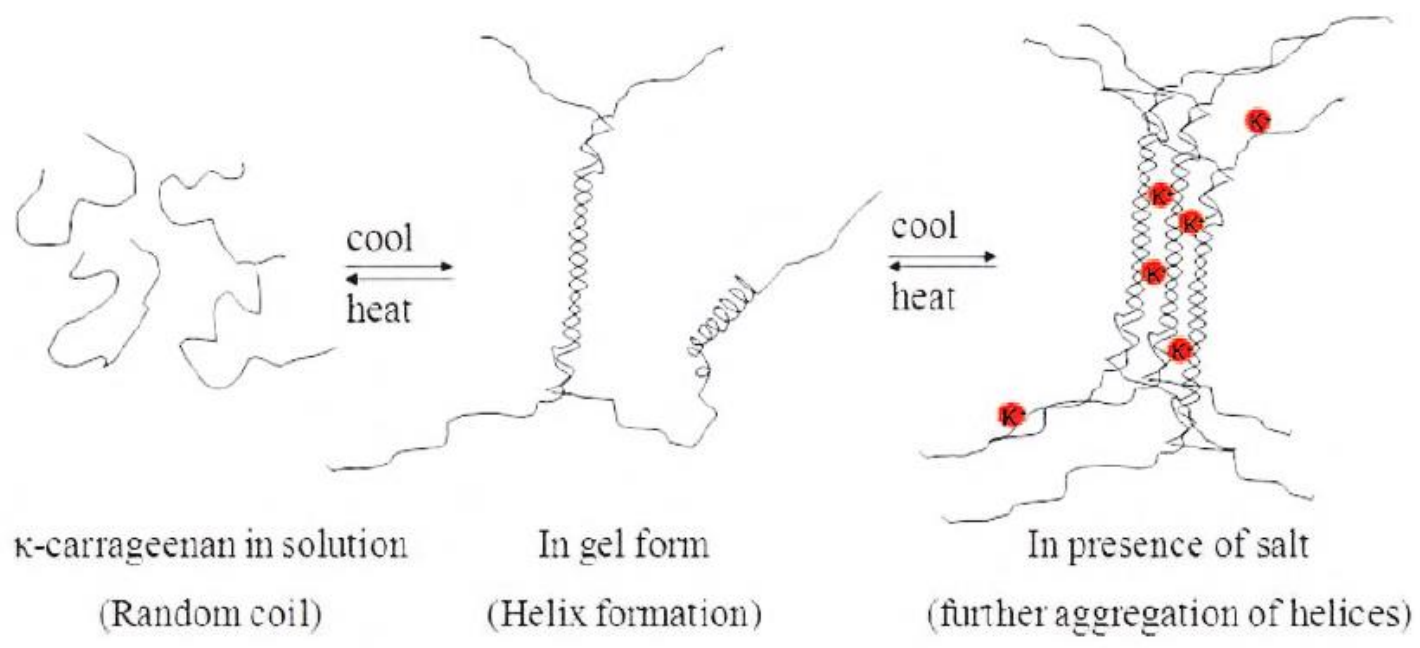

Figure 2 Carrageenan coil formation (Gulrez and Al-Assaf 2011)

K-carrageenan is often added in small quantities to polysaccharide and milk mixed solutions to prevent separation, however the mechanism of interaction is not well understood. Several studies have looked at the relationship between $\mathrm{K}$-carrageenan and K-casein (Bourriot and others 1999a; Thaiudom and Goff 2003; Spagnuolo and others 2005; Ji and others 2008). Historically, it was thought that the conformation of $\mathrm{k}$ carrageenan was able to penetrate the hairy surface layer of $\mathrm{k}$-casein to adhere to the positively charged patches of the casein micelle (Snoeren and others 1975). Conversely, more recent research confirmed that at low concentrations of $\mathrm{k}$-carrageenan the casein micelle diameter was linearly related to the $\mathrm{k}$-carrageenan concentration indicating that the carrageenan was able to adhere to the micelle interfacial surface ( $\mathrm{Ji}$ and others 2008). At higher concentrations, the observed difference may be due to $\mathrm{K}$-carrageenan 
gel network interactions surrounding the casein micelles. Since k-carrageenan is sensitive to gelation in the presence of calcium ions, when in the presence of milk calcium it prevents macro-phase separation to a higher degree than other polysaccharides (Bourriot and others 1999a).

\subsection{Protein polysaccharide interactions}

A previous literature review by de Kruif and Tunier (2001) found that the interaction of protein polymers with added polysaccharides in a mixed biopolymer system could be characterized in three different ways. At low concentrations, mixed biopolymer systems are stable and the polymers are co-soluble. However, at higher concentrations oppositely charged polymers will attract each other and form an insoluble complex, while same charged polymers will repel each other and cause phase separation. The micellar structure of casein with the $\mathrm{k}$-casein brush border limits its interactions with polysaccharides. Most casein polysaccharide systems exhibit phase separation through depletion interactions between the polymers. Dissociated casein aggregates made by heat treatment or reduction in electrostatic charge are better able to interact with charged polysaccharides (McMahon and others 2009; Dalgleish and Corredig 2012).

When solutions of native whey protein and polysaccharides are heated together at a $\mathrm{pH}$ above $\mathrm{pl}$, the positive patches of the protein that are exposed during unfolding are able to interact with the negatively charged polysaccharides to form a heated soluble complex. A study of whey protein foam properties found that heating the whey protein with $\lambda$-carrageenan led to increased foamability and improved drainage $1 / 5$ life. 
These changes are attributed to protein-polysaccharide interactions improving elasticity and film viscosity of the foam (Wang 2013).

Whey protein-polysaccharide heated soluble complexes have also been applied to acid-induced gelation. Interactions between the polysaccharides and the proteins can alter gel properties and microstructure (Cavallieri and Cunha 2009). In studies with pectin, complex formation at $\mathrm{pH} 7$ and the use of the highest charge density pectin were able to improve acid induced gel strength and water holding capacity (Zhang and others 2014; Zhang and Vardhanabhuti 2014).

\subsection{Summary}

Protein based foams and gels are an important segment of the food industry. Aerated gels combine the properties of foams and gels in novel textured foods that have the potential to offer improved nutritional profiles. While the destabilization mechanisms of foams and gels are well understood, little research has been done on controlling the properties of aerated gels. A dairy based system containing both casein and whey protein can be used to create successful aerated gels. Previous research on whey protein-polysaccharide heated soluble complexes made with high charge density polysaccharides have shown them to be effective in improving the desired properties of foams and gels. They may also be effective in stabilizing aerated gels. 


\title{
CHAPTER 3 MANUSCRIPT 1: PECTIN
}

\author{
Manuscript to be Submitted to the Journal of Dairy Science
}

\subsection{Abstract}

Heated soluble complexes of whey protein isolate (WPI) with polysaccharides may be used to modify the properties of aerated dairy gels, which could be formulated into novel-textured high-protein desserts. The objective of this study is to determine the effect of polysaccharide charge density and concentration within a WPI-polysaccharide complex on the properties of aerated gels. Three polysaccharides having different degrees of charge density were chosen: low methoxyl pectin (LM-12), high methoxyl type D pectin (HM-D), and guar gum. Heated complexes were prepared by heating the mixed solutions ( $8 \%$ protein, 0 to $1 \%$ polysaccharide) at $\mathrm{pH} 7$. To form aerated gels, $2 \%$ glucono- $\delta$-lactone (GDL) was added to the solutions and foam was generated by whipping with a handheld frother. The foam set into a gel as the GDL acidified to a final $\mathrm{pH}$ of 4.2. The aerated gels were evaluated for overrun, drainage, gel strength, and viscoelastic properties.

Overrun of aerated gel decreased as polysaccharide concentration increased due to increased viscosity which limited air incorporation. A negative relationship was found between percent drainage and solution viscosity. However, plotting of drainage against solution viscosity separated by polysaccharide type revealed that drainage improved 
most in samples with high charge density WPI-LM-12 followed by those with low charge density WPI-HM-D. Aerated gels with guar gum (no charge) did not show improvement in stability. Rheological results showed no significant difference in gelation time among samples; therefore, stronger interactions between WPI and high charge density polysaccharide were likely responsible for increased stability.

Stable dairy aerated gels can be created from WPI-polysaccharide complexes. High charge density polysaccharides, at concentrations that provide adequate viscosity, are needed to achieve stability while also maintaining solution overrun capabilities.

\subsection{Introduction}

As a byproduct of cheese manufacturing, whey protein can be an economic and environmental burden when unused. Alternatively, its high biological value protein content and unique properties make it a promising food ingredient (Smithers 2008). Whey protein is commonly added to dairy foods such as yogurt, ice cream, and cheese to increase total protein content, alter textures, or replace more costly ingredients (Singleton 1973; Kinsella and Whitehead 1989; Sodini and others 2005). Understanding whey protein functional properties that allow it to support different food textures is crucial to expanding its use to new applications in the food industry.

There is opportunity to expand the use of whey protein in nutritionally focused products. As consumers look for more healthful food choices there is interest in foods that are more filling with less calories. Putting whey protein into an aerated system can address consumer's desire to lower calorie intake in two ways. Proteins as a class are more satiating than carbohydrates or fat and whey protein may suppress 
gastrointestinal hormones to further improve satiation. (Hall and others 2003; Veldhorst and others 2009). Additionally, adding bubbles to snack foods such as chocolate or cheese puffs introduces a novelty factor (Campbell and Mougeot 1999) and has been shown to decrease energy intake by increasing the total food volume per calorie (Osterholt and others 2007). Although whey protein foaming and gelation properties are well understood, little research has been done on aerated whey protein gels.

There is a long history of aerating foods through several methods including; whipping, gas injection, steam generation, or fermentation. Many aerated foods such as soufflés, ice cream, and whipped cream rely on fat molecules to support the aerated network (Campbell and Mougeot 1999; Allen and others 2006). In a nutritionally focused product, fat content may be undesirable, so additional stabilization mechanisms are needed. The functional properties of whey protein can be exploited to prevent system destabilization such as drainage, coalescence, or disproportionation.

In a foam system, stability can come from increased solution viscosity, increased interfacial elasticity, or control of bubble size. The amphiphilic nature of whey protein allows it to interact with both the air and water phase of the foam interface. Native whey proteins are able to adhere quickly to the interface to increase stability during the foaming process. When heated, the whey proteins form aggregates or polymers, resulting in slower interfacial adsorption due to their larger size. However, they are better able to stabilize the foam by increasing the interfacial elasticity which increases resistance to deformation forces (Davis and Foegeding 2004; Schmitt and Turgeon 2011). The introduction of polysaccharides into the foam solution can work in 
conjunction with either native whey protein or whey protein polymers to further stabilize the foam. Polysaccharides increase the solution viscosity which contributes to foam stability, however their electrostatic charge also plays an important role. By interacting with oppositely charged regions on the protein the polysaccharide can modify its function at the interface within a range of $\mathrm{pH}$ (Schmitt and Turgeon 2011).

Further research on the relationship of whey protein and polysaccharides focuses on their properties when co-heated as a complex. Typically in a mixed system with two charged polymers such as whey proteins and polysaccharides, they will either segregate into a bilayer system, or attract and form insoluble aggregates (de Kruif and Tuinier 2001). However, when solutions of native whey protein and polysaccharides are heated together at a pH above the protein isoelectric point (pl), the positive patches of the protein that are exposed during unfolding are able to interact with the negatively charged polysaccharides to form a heated soluble complex. A study of whey protein foam properties found that heating the whey protein with $\lambda$-carrageenan led to increased foamability and increased drainage $1 / 5$ life. These changes are attributed to protein-polysaccharide interactions improving elasticity and film viscosity of the foam (Wang 2013).

Whey protein-polysaccharide heated soluble complexes have also been applied to acid-induced gelation. When whey proteins in solution are subjected to gradually lowering $\mathrm{pH}$, the change in the net electric charge of the aggregates allows them to interact and form a gel network (Alting and others 2002). The addition of polysaccharides to the system can be used to alter gel properties and microstructure 
(Cavallieri and Cunha 2009). A number of polysaccharide chemical properties have an effect on the gel microstructure. Charge density has the largest effect, followed by molecular weight and chain stiffness (de Jong and van de Velde 2007). Recent works have shown that acid-induced gels formed from heated whey protein-polysaccharide complexes have improved water holding capacity and gel strength compared to those from whey protein polymers with added polysaccharides (Zhang and others 2014; Zhang and Vardhanabhuti 2014).

We would like to investigate whether heated whey protein-polysaccharide complexes could be applied to stabilize aerated whey protein gels by combining their properties in improving both foam and acid-induced gels. To evaluate the effect of both polysaccharide concentration and electrostatic charge on the final foam and gel properties, two pectins were chosen for this study. Low-methoxyl pectin (LM-12) is manufactured with a high degree of esterification and has a high negative charge. Highmethoxyl pectin (HM-D) has a lower degree of esterification and a lower charge. Guar gum was also included in this study as a control polysaccharide with neutral charge.

The objective of this study was to investigate the effect of heated whey proteinpolysaccharide complexes on low pH aerated skim milk gel. Several polysaccharides were used in the system to look at the roles charge density and polysaccharide concentration play on the stability of the aerated system during the acid-induced gelation process. A greater understanding of how heated complex addition can be used to maintain product stability while manipulating properties, such as overrun and yield stress, will allow the dairy industry to create successful novel-textured products. 


\subsection{Materials and methods}

\subsubsection{Materials}

Whey Protein Isolate (WPI) containing $93.4 \%$ protein was donated by Davisco Foods Intl. (Le Sueur, MN). Skim milk powder (SMP) containing 35\% protein was obtained from a bulk manufacturer. Polysaccharides (PS) consisted of low methoxyl LM12 and high methoxyl HM type D pectins (CP Kelco, Atlanta, GA), and guar gum (TIC Gums, Belcamp, MD). Acidulation was achieved with either glucono- $\delta$-lactone (GDL) provided by Sigma-Aldrich Corp. (St. Louis, MO) or yogurt cultures containing Streptococcus thermophilus and Lactobacillus bulgaricus provided by DuPont Danisco (Madison, WI). All other chemicals are of analytical grade.

\subsubsection{Biopolymer Preparation}

WPI stock solution (15\% protein $\mathrm{w} / \mathrm{w}$ ) was formed by dissolving protein powder in deionized (DI) water and slowly stirring at room temperature for $\geq 4$ hours for complete hydration. A dispersion of SMP (23.5\% solids, $8 \%$ protein $\mathrm{w} / \mathrm{w}$ ) was made in a similar manner. After full hydration, the SMP was held in a $99.9{ }^{\circ} \mathrm{C}$ water bath until it reached $>90^{\circ} \mathrm{C}$ for 5 minutes. Then, it was cooled in an ice bath and held at $5 \circ \mathrm{C}$ prior to use. Pectins $(4 \% \mathrm{w} / \mathrm{w})$ were stirred on a hotplate to a temperature of $60 \circ \mathrm{C}$, then stored at 5 으 overnight. Guar gum powder was mixed quickly into cold water $(1.33 \% \mathrm{w} / \mathrm{w})$ and also stored overnight prior to use.

\subsubsection{Formation of Heated WPI-PS Complexes}

WPI and polysaccharides were mixed at appropriate amount and their $\mathrm{pH}$ was adjusted to 7.0 with 0.1 and $0.01 \mathrm{~N} \mathrm{NaOH}$. DI water was added such that the final 
protein concentration was $8 \%(\mathrm{w} / \mathrm{w})$ and polysaccharide concentration ranging from 0 to $1 \%(\mathrm{w} / \mathrm{w})$. The mixtures were gently stirred at room temperature for $2 \mathrm{~h}$ before being heated in a temperature-controlled water bath at $85^{\circ} \mathrm{C}$ for $30 \mathrm{~min}$ and cooled in an ice bath. The cooled WPI-PS complexes were then mixed with the heated skim milk in a 60:40 weight ratio. Deionized water was added to all the samples to produce the final protein concentration of $7 \%$. The finished samples were stored at $50 \mathrm{C}$ overnight prior to testing for complete interaction between protein and polysaccharide.

\subsubsection{Viscosity Measurement}

Viscosity measurement was conducted on polysaccharide as well as mixed systems of SMP and heated WPI-PS complex solutions. Polysaccharide solutions were prepared from the stock solutions, diluted with $\mathrm{DI}$ water and $\mathrm{pH}$ adjusted to 7.0.

Viscosity was measured on a Kinexus Pro rheometer (Malvern Instruments Ltd, Worcestershire, UK) using a $65 \mathrm{~mm}$ diameter lower plate and $40 \mathrm{~mm}$ diameter 4 을 cone upper geometry with $0.15 \mathrm{~mm}$ gap. Shear rate was increased from 0.1 to $100 \mathrm{sec}^{-1}$ at $25 \circ \mathrm{C}$

\subsubsection{Acid-Induced Gelation}

GDL was added to the treatments at $2 \% \mathrm{w} / \mathrm{w}$ (GDL/total) for all samples except the skim milk control which required $3.5 \% \mathrm{w} / \mathrm{w}$ to reach the same $\mathrm{pH}$ of $4.5 \pm 0.1$ after $24 \mathrm{~h}$ of storage at $5 \stackrel{\circ}{ } \mathrm{C}$. The mixtures were gently stirred for $30 \mathrm{~s}$ and then three $1.5 \mathrm{~mL}$ aliquots were transferred to microcentrifuge tubes for water holding capacity measurement. Samples were covered with parafilm and left overnight at $4^{\circ} \mathrm{C}$. All testing was completed within $24 \pm 1$ hours of GDL addition. 
Gel Texture Analysis. Gel samples were removed from the fridge and allowed to equilibrate to room temperature for two hours prior to testing. A TA-HDi Texture Analyzer (Texture Technologies Corp., Scarsdale, N.Y.,) equipped with a $5 \mathrm{~kg}$ load cell operated at a test speed of $10 \mathrm{~mm} / \mathrm{s}$ measured force in compression with a $13 \mathrm{~mm}$ diameter stainless steel probe. The penetration distance was fixed to $10 \%$ of the original gel thickness $(30 \mathrm{~mm}$ ) and was held for $300 \mathrm{~s}$. The peak force for each sample was recorded.

Water Holding Capacity. Gel samples (1.5 g) in centrifuge tubes were removed from the fridge and allowed to equilibrate to room temperature for two hours prior to testing. Gelled samples were placed in a micro-centrifuge operating at 10,000 RPM $(9,037 \mathrm{~g})$ for 10 minutes. The free liquid was removed from the top of each sample by micropipette and weighed in $\mathrm{mg}$. The measurements were completed in triplicate. The percent water holding capacity (WHC) was calculated from the recorded weight of free liquid with the equation: $\frac{(1500-\text { recorded wt in } \mathrm{mg})}{1500} \times 100$

\subsubsection{Formation of aerated gel}

For consistent foaming conditions, foam samples were created by placing $40 \mathrm{~g}$ of each test treatment into a $250 \mathrm{~mL}$ beaker. GDL was added (28.6 mg GDL per g of protein) and the samples were stirred quickly for 30 seconds to dissolve the crystals. Immediately after GDL addition, the samples were whipped for 2 minutes with a hand held Aerolatte ${ }^{\circledR}$ frothing wand (Aerolatte Ltd, Radlett, UK) connected to a 3.7 volt, 0.35 
amp power adapter for consistent power supply. All foam property measurements were taken immediately after aeration.

Drainage. To measure the degree of liquid drainage from the foam before gelation set in, the aerated solution was poured into a $15 \mathrm{~mL}$ centrifuge tube until it was level with the top $(15.75 \mathrm{ml}$ total volume). The weight of the foam in the tube was recorded. After 15 minutes, the aerated solution had gelled and the volume of liquid which had drained from the foam and collected at the bottom of the tube was recorded. The percent drainage was calculated using the equation:

$$
\frac{\text { mL of drained liquid } x \text { density }}{\text { total weight of foam in tube }} \times 100
$$

Overrun. Immediately after whipping, foam overrun was measured by gently transferring the foam into a pre-weighed $35 \mathrm{~mm}$ diameter $\times 10 \mathrm{~mm}$ petri dish $(9.62 \mathrm{~mL}$ total volume). The dish was filled to above the rim, then a metal spatula was used to level off the top of the foam for consistent volume before recording the weight. The measurement was completed in triplicate. The percent overrun was calculated using the equation: $\frac{(9.62 \times \text { density })-\text { recorded weight }}{\text { recorded weight }} \times 100$

\subsubsection{Viscoelastic Properties}

Further study of small scale deformation of the aerated gels was conducted on samples containing $0.315 \%$ polysaccharides. This concentration was chosen because it was the first to form a stable aerated gel (for WPI-LM-12). Samples with lower polysaccharide concentrations were excluded because the liquid drainage from the foam created a non-homogenous structure. 
Immediately after whipping, foams were gently loaded into the Kinexus Pro Rheometer with a plate and plate geometry (50 $\mathrm{mm}$ upper plate) with a $1 \mathrm{~mm}$ loading gap. The excess foams were gently removed and the solvent trap was used to prevent sample drying. The development of elastic modulus $\left(G^{\prime}\right)$ was monitored in the linear region ( $0.5 \%$ strain) at a constant frequency of $1 \mathrm{~Hz}$ at $25 \circ \mathrm{C}$ for 6 hours. Sample gelation time was determined by recording the point where the change in $\mathrm{G}^{\prime}$ during gel formation is discernable from background noise as defined by Horne (1999). G' at 6 hours after GDL addition was chosen to represent the final G'.

For yield stress measurement, after whipping, foam was gently loaded on the Kinexus Pro Rheometer using $40 \mathrm{~mm}$ serrated upper and lower plates with a $1 \mathrm{~mm}$ gap. The excess foams were gently removed and the solvent trap was used to prevent sample drying. Aerated gel was allowed to form in situ for $2 \mathrm{hr}$. A single shear rate of 0.01 was applied for 10 minutes. Yield stress was defined as the peak recorded shear stress $(\sigma)$.

\subsubsection{Lactic Acid Bacteria Gelation}

Yogurt starter cultures containing Streptococcus thermophilus and Lactobacillus bulgaricus were added at $0.01 \%$ concentration to the sample solution as recommended by the manufacturer. After 30 minutes of gentle stirring at room temperature, the samples were foamed, poured into $15 \mathrm{~mL}$ centrifuge tubes, and incubated at $42 \circ \mathrm{C}$ for 6 hours. After incubation, drainage measurements were conducted in the same manner as for the GDL samples. The sample $\mathrm{pH}$ was also recorded. 


\subsubsection{Statistical Analysis}

Statistical analysis was completed with SAS version 9.3 (SAS Institute Inc., Cary, IN). All values are means \pm SD. Statistical differences were analyzed using PROC GLM for ANOVA followed by the Tukey-Kramer test, and for regression analysis. $P$ values $<0.05$ were considered statistically significant. All statistical analysis was done on at least 2 replications.

\subsection{Results and discussion}

The formation of the aerated gels in this study was done with a handheld frother, a relatively new method that is also found in a previous study on lactoglobulin and casein foam coarsening (Blijdenstein and others 2010). Preliminary tests of overrun and drainage on SMP with heated WPI-polysaccharide complexes showed that the test repeatability was good if both the time between sample mixing and testing, and the time between GDL addition and testing, were controlled (results not shown).

\subsubsection{Aerated Gel Overrun}

Overrun of aerated gels ranged from $30.6 \pm 2.9$ to $121 \pm 4$ for SMP gels with heated WPI-LM 12 complexes (WPI-LM12), 14.1 \pm 1.2 to $120 \pm 2$ for heated WPI-HM D complexes (WPI-HM D), and 20.0 \pm 3.8 to $98 \pm 6$ for heated WPI-Guar gum complexes (WPI-Guar). As expected, overrun decreased significantly as polysaccharide concentration increased $(P<0.0001)$ (Figure 3A). This effect was seen in all three concentration types (Figure 3B). The presence of polysaccharide leads to increased viscosity of pre-foam solution and thus limits air incorporation during frothing. Several studies have reported the negative correlation between overrun of protein foams and the viscosity of pre-foam solutions at 
the shear rate corresponding to whipping shear rate (Campbell and Mougeot 1999;

Mott and others 1999; Pintor and Totosaus 2012) (Figure 4A). Since the exact shear rate of the Aerolatte ${ }^{\circledR}$ frother is not known, we have analyzed the relationship between the overrun and the viscosity at shear rates of 50,80 , and $100 \mathrm{sec}^{-1}$. The same relationships were found at all three shear rates. There were significant differences in the high shear viscosity for each of the polysaccharide types and high shear viscosity was found to be a strong predictor of foam overrun $(\mathrm{P}<0.0001)$ (Figure 4B). Viscosity values at shear rate $100 \mathrm{sec}^{-1}$ were chosen to be reported in this article's tables and figures. 

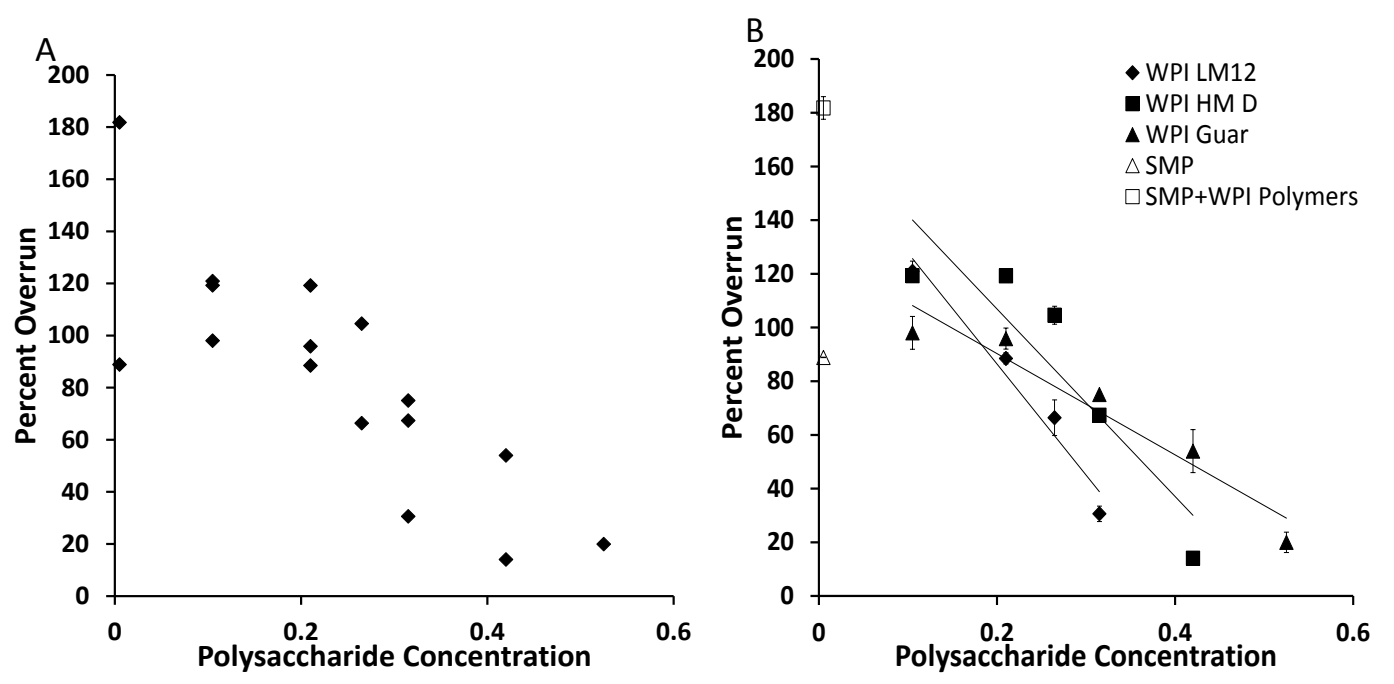

Figure 3 Percent overrun of aerated gels with different polysaccharide concentrations of A) all samples B) samples organized by type
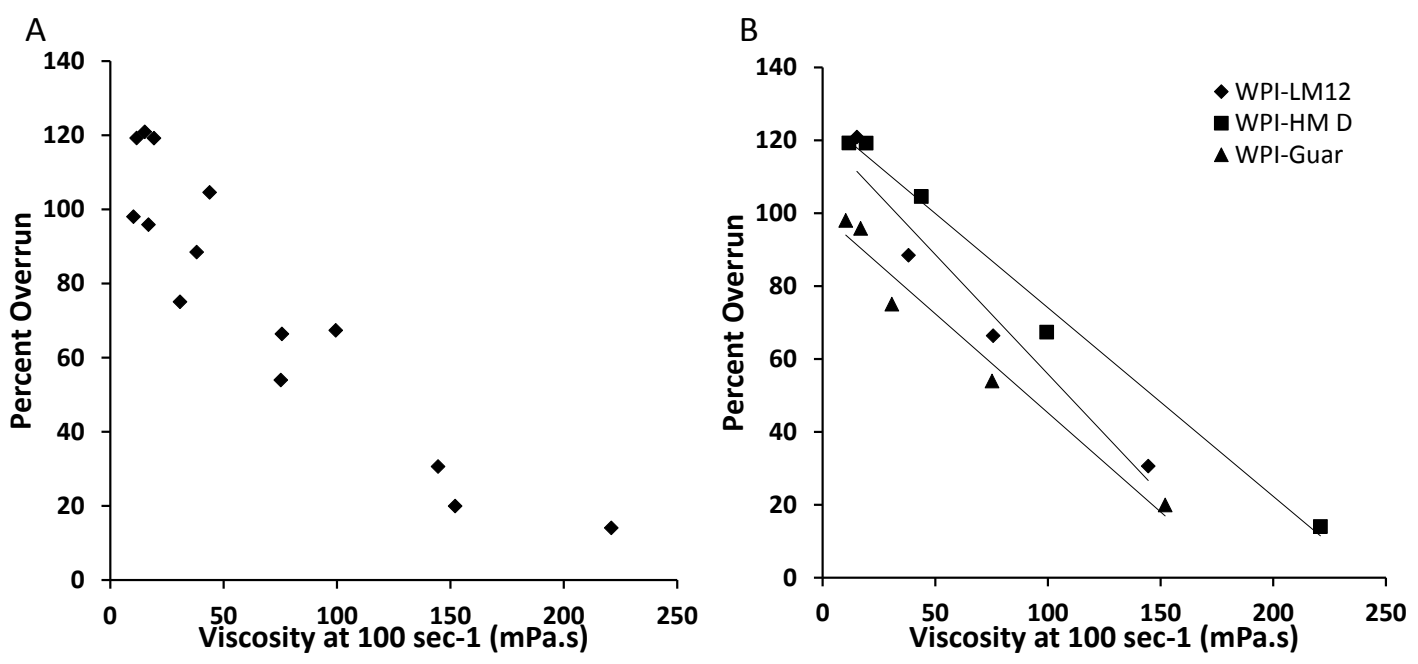

Figure 4 Percent overrun of aerated gels versus viscosity at $100 \mathrm{sec}^{-1}$ for A) all samples B) samples organized by type 
As samples with higher viscosity have lower overrun, it is expected that increasing polysaccharide concentration will also decrease overrun due to increased viscosity. The control sample containing heated SMP and WPI polymers with no polysaccharides had by far the highest overrun $178 \pm 4 \%$. However that sample is unsuitable for an aerated gel product due to its poor stability. This demonstrates that when comparing polysaccharides it is important to compare the overruns of the stable aerated gels with no drainage. The complex containing the higher charge density polysaccharide (WPI-LM12) was able to stabilize at lower concentration and thus lower

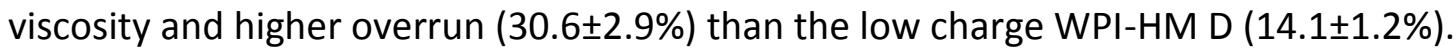
This indicates that high charge density polysaccharides will allow formulations with a wider range of possible overruns.

\subsubsection{Stability of Aerated Gels}

Drainage, an indicator of foam stability, is generally measured as the time it takes for half of the foam by weight to drain from its container or for half of the height of the foam to collapse within a column (Lau and Dickinson 2005). With aerated gels, the loss of foam stability can be seen as the volume of liquid that drains from the foam before gelation occurs (Tomczynska-Mleko 2013). In samples with no drainage, air bubbles can be seen spread evenly throughout the gel network. When drainage occurs, a two phase system forms with the air bubbles creaming at the top of the container and a distinct gel layer with no air at the bottom. Collapsing of the foam resulting in a decrease in volume was only seen in the least stable SMP control samples. Here, 
stability is expressed as percent drainage by weight to control for the change in total aerated gel weight at the same volume with varied overruns.

Without heated complexes, SMP alone could not form stable aerated gels;

drainage began immediately after aeration. Stable aerated gel was also not achieved when heated whey proteins (WPI-polymers) were used. It should be noted that addition of polysaccharide to SMP (without WPI) is not advised due to depletion interactions that typically occur between casein and polysaccharides and cause phase separation (de Kruif 1999). Replacing $60 \%$ of the SMP with heated complexes resulted in decreased drainage of aerated gels. Stability was significantly affected by polysaccharide concentration $(P<0.0001)$ (Figure $5 A)$ and the type of polysaccharides $(P<0.0001)$. Increasing polysaccharide concentration resulted in a decrease in percent drainage across all polysaccharides except guar gum at $0.525 \%$ (Figure 5B). Complete stability (no drainage) was achieved at $0.315 \%$ and $0.415 \%$ of WPI-LM12 and WPI-HM D, respectively. Percent drainage of aerated gels formed with heated WPI-Guar could only be reduced to $38 \%$. The percent drainage for WPI-LM12 ranged from $0 \pm 0$ to $65.9 \pm 1.3$, from $0 \pm 0$ to $70.4 \pm 0.08$ for WPI-HM D and from $38.1 \pm 2.1$ to $75.6 \pm 1.32$ for WPI-Guar. 

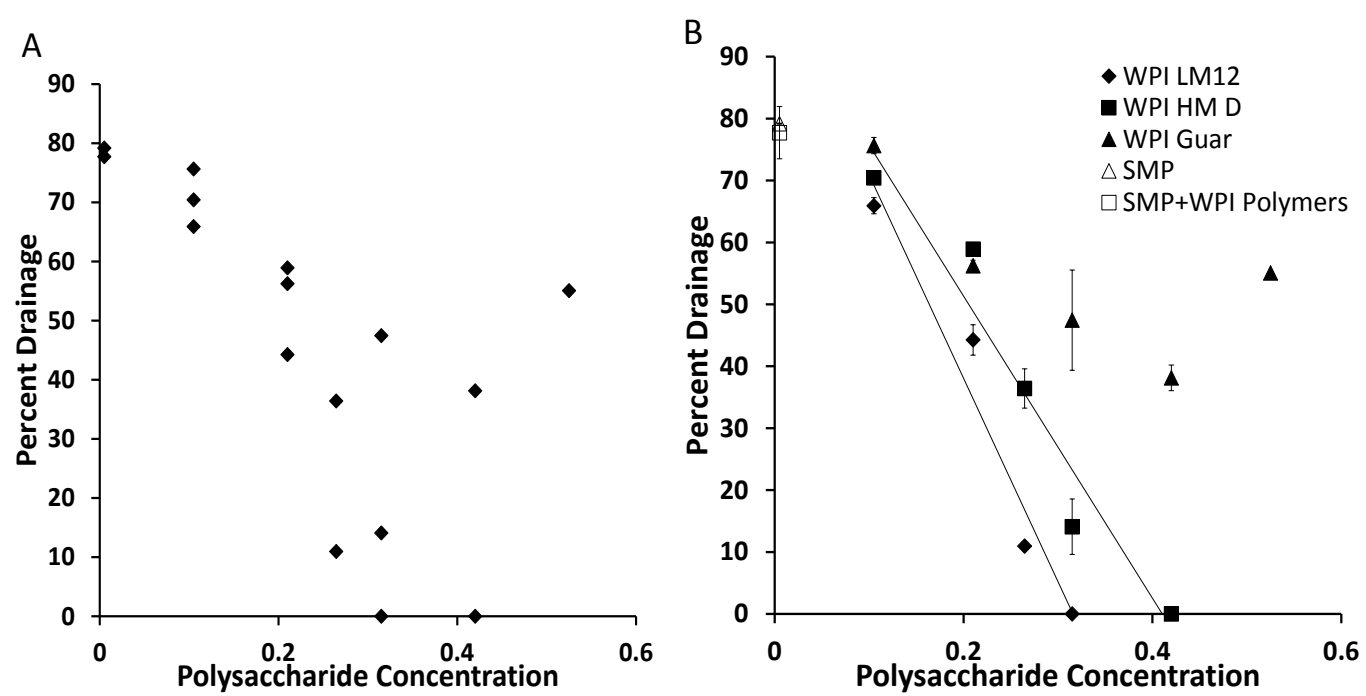

Figure 5 Percent drainage of aerated gels with different polysaccharide concentrations of $A$ ) all samples $B$ ) samples organized by type 
Table 1 Effect of Viscosity on Drainage and Overrun

\begin{tabular}{|c|c|c|c|c|c|c|c|}
\hline Type & $\begin{array}{c}\text { Final PS } \\
\text { Concent- } \\
\text { ation }\end{array}$ & $\begin{array}{c}\text { Polysaccharide } \\
\text { Viscosity } \\
\text { (mPa.s) }\end{array}$ & $\begin{array}{c}\text { WPI-PS } \\
\text { Complex } \\
\text { Viscosity* } \\
\text { (mPa.s) }\end{array}$ & $\begin{array}{c}\text { SMP-Cmpx } \\
\text { mixture } \\
\text { Viscosity* } \\
\text { (mPa.s) }\end{array}$ & $\begin{array}{c}\text { SMP-Cmpx } \\
\text { mixture } \\
\text { Viscosity** } \\
\text { (mPa.s) }\end{array}$ & $\begin{array}{c}\text { Percent } \\
\text { Overrun }\end{array}$ & $\begin{array}{c}\text { Percent } \\
\text { Drainage }\end{array}$ \\
\hline WPI-LM12 & 0.105 & $1.64 \pm 0.53$ & & $21.6 \pm 0.15$ & $15.2 \pm 0.1$ & $121 \pm 4$ & $65.9 \pm 1.3$ \\
WPI-HM D & 0.105 & $2.02 \pm 0.41$ & & $12.5 \pm 0.2$ & $11.6 \pm 0.2$ & $119 \pm 2$ & $70.4 \pm 0.1$ \\
WPI-Guar & 0.105 & $16.4 \pm 1.6$ & & $13.5 \pm 0.1$ & $10.2 \pm 0.3$ & $98.0 \pm 6.1$ & $75.7 \pm 1.3$ \\
\hline WPI-LM12 & 0.210 & $1.91 \pm 0.01$ & & $63.1 \pm 0.8$ & $38.1 \pm 0.3$ & $88.5 \pm 2.1$ & $44.3 \pm 2.5$ \\
WPI-HM D & 0.210 & $2.78 \pm 0.22$ & & $23.0 \pm 1.0$ & $19.3 \pm 0.8$ & $119 \pm 1$ & $58.9 \pm 0.5$ \\
WPI-Guar & 0.210 & $24.9 \pm 3.8$ & & $16.9 \pm 0.04$ & $16.8 \pm 0.4$ & $95.9 \pm 3.9$ & $56.2 \pm 0.9$ \\
\hline WPI-LM12 & 0.265 & $2.22 \pm 0.07$ & & $129 \pm 18.3$ & $75.7 \pm 23.6$ & $66.4 \pm 6.6$ & $11.0 \pm 0.2$ \\
WPI-HM D & 0.265 & $5.76 \pm 2.84$ & & $70.5 \pm 12.2$ & $43.8 \pm 3.1$ & $105 \pm 3$ & $36.4 \pm 3.2$ \\
\hline WPI-LM12 & 0.315 & $2.51 \pm 0.02$ & $142 \pm 3$ & $540 \pm 78$ & $145 \pm 4$ & $30.6 \pm 2.9$ & $0 \pm 0$ \\
WPI-HM D & 0.315 & $4.49 \pm 0.64$ & $181 \pm 5$ & $416 \pm 32.8$ & $99.5 \pm 2.5$ & $67.4 \pm 0.5$ & $14.1 \pm 4.5$ \\
WPI-Guar & 0.315 & $77.9 \pm 4.2$ & $170 \pm 9$ & $26.5 \pm 3.2$ & $30.7 \pm 1.4$ & $75.1 \pm 0.8$ & $47.5 \pm 8.1$ \\
\hline WPI-HM D & 0.42 & $4.22 \pm 0.28$ & & $536 \pm 39$ & $221 \pm 7$ & $14.0 \pm 1.2$ & $0 \pm 0$ \\
WPI-Guar & 0.42 & $206 \pm 3$ & & $137 \pm 22$ & $75.2 \pm 3.1$ & $54.0 \pm 8.0$ & $38.1 \pm 2.1$ \\
WPI-Guar & 0.525 & $384 \pm 20$ & & $306 \pm 6$ & $152 \pm 0$ & $20.0 \pm 4$ & $55.1 \pm 0.2$ \\
\hline
\end{tabular}

Values are means \pm SD

* Viscosity measured at $8 \mathrm{sec}^{-1}$ shear rate

** Viscosity measured at $100 \mathrm{sec}^{-1}$ shear rate 
As viscosity is so influential on overrun and stability outcomes, the relationship between viscosity and charge density was further investigated (Table 1). Viscosities were measured of the polysaccharides in DI water at the same concentration as they are in the aerated gels, of the WPI-Polysaccharide complexes at $0.315 \%$ concentration, and the WPI-polysaccharide SMP mixture used to make the aerated gel at all concentrations. The trend for viscosity at $8 \mathrm{sec}^{-1}$ of the polysaccharide solutions shows that at every concentration guar gum is significantly more viscous than LM-12 or HM D pectins. This is expected as guar gum is known to be highly thickening (Bourriot and others 1999b).

When the polysaccharides were mixed with WPI and heated to form soluble complexes, the viscosity trend changes. For the pectin containing samples, the viscosity of the WPI-PS complex was drastically increased. This is partially due to the intrinsic viscosity of the WPI that had been introduced to the solution, but also due to the formation of soluble complexes. The WPI-pectin complexes have particle diameter in the range of 50-100 $\mathrm{nm}$ (Zhang and others 2012) which contributes to solution viscosity. The WPI-guar gum complex viscosity was also increased, but to a smaller extent. This may be related to the lack of complex formation between WPI and the neutrally charged guar gum.

The sample viscosities change yet again when the complexes were mixed with heated SMP to make the solution used for the aerated gels. These solutions have a higher total solids content. The pectin containing samples have a very high viscosity at $8 \mathrm{sec}^{-1}$ shear rate, and undergo shear thinning with a lower viscosity at $100 \mathrm{sec}^{-1}$. Interestingly, the WPI-guar samples viscosity is lower at both shear rates than the 
polysaccharide or complex viscosity. When the casein micelles in the SMP interact with the guar gum they experience depletion related phase separation which limits the overall viscosity.

Returning to the drainage results, the measurements of polysaccharide viscosity and solution viscosity were used to analyze the relationship of viscosity with drainage. Low shear viscosity of $8 \mathrm{sec}^{-1}$ was used to represent the shear forced exerted by gravity. No relationship was found between the viscosity of just the polysaccharide being added to the system, and final sample stability (Figure 6). This indicates that aerated gel drainage cannot be improved simply by choosing a high viscosity polysaccharide. When the viscosity of the sample solutions was plotted against sample percent drainage a negative relationship is seen $(\mathrm{P}=<0.0001)$ (Figure $7 \mathrm{~A})$. The effect of viscosity on drainage was significantly different for each of the three polysaccharides $(P=0.0005)$. The improvement in drainage for the same increase in viscosity is different based on the charge density of the polysaccharide within the complex (Figure 7B). The WPI-LM12 sample percent drainage decreases at a slope of -21.4. The lower charge WPI-HM D samples have a slope of -17.4. No relationship was found for guar gum between drainage and viscosity. 


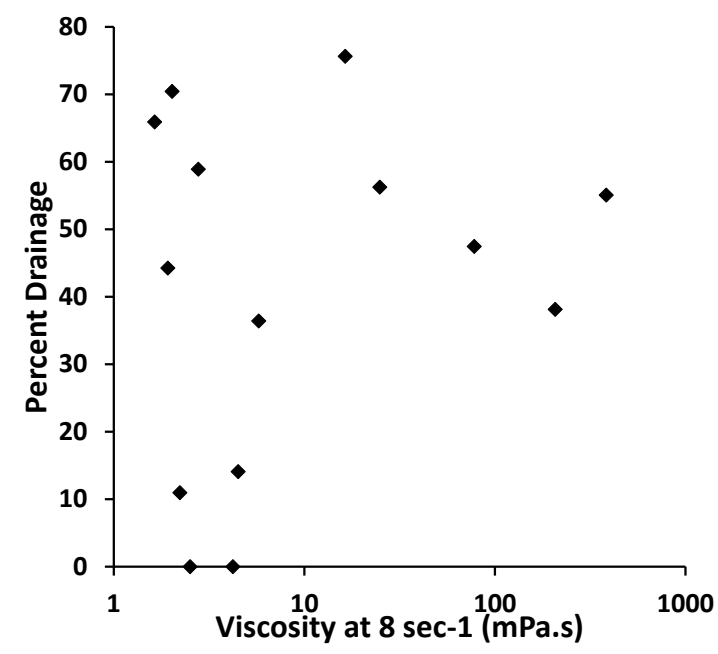

Figure 6 Percent drainage of aerated gel versus polysaccharide viscosity at $8 \mathrm{sec}^{-1}$
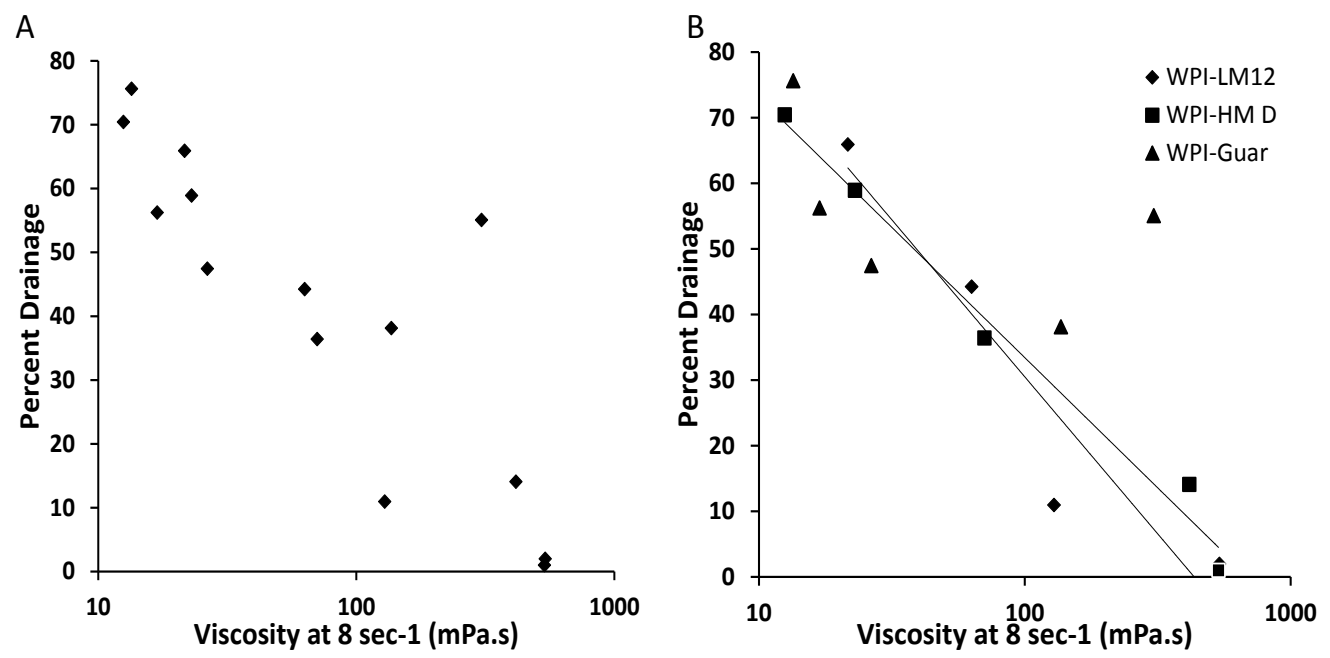

Figure 7 Percent drainage of aerated gel versus SMP-complex viscosity at $8 \sec ^{-1}$ for A) all samples $B$ ) samples organized by type 


\subsubsection{Water Holding Capacity}

There is no difference in the water holding capacity (WHC) for the WPI-pectin samples at any concentration (results not shown). The average measured WHC was $96.7 \% \pm 0.95$ for all samples excluding the $0.315 \%$ concentration of guar gum which had $67.33 \% \pm 1.7$ WHC. WHC was not measured on samples with polysaccharide concentrations higher than $0.315 \%$.

It's expected that all the samples containing WPI-Pectin and the lower concentrations of WPI-Guar would have similar WHC results. Previous research established that heated WPI-polysaccharide complexes have high WHC at these concentrations; differences based on charge density are not seen until higher polysaccharide concentrations (Zhang and Vardhanabhuti 2014). Poor WHC is associated with high drainage as was seen with the $0.315 \%$ WPI-Guar sample with high drainage related phase separation before gelation. WHC is also an important indicator of shelf life as it is linked to syneresis defects in gels (Keogh and O'Kennedy 1998). Samples with high WHC that were stored for 14 days at 5ㅇ did not display any further syneresis in a preliminary shelf life trial (results not shown).

\subsubsection{Viscoelastic Properties}

The viscoelastic properties of protein based gels and foams are effected by acidulation rate and solution pH (Allen and others 2006; Zhang and others 2014). Among our samples no significant difference was found for gelation time of the three polysaccharide types $(P=0.061)$. Additionally the samples all had a pH of $4.49 \pm 0.0524 \mathrm{~h}$ after GDL addition. This indicates that viscoelastic differences found can be attributed to 
the differences among the WPI-polysaccharide complexes. The elastic modulus ( $\left.G^{\prime}\right)$ is a measure of gel deformation under shear forces and relates to gel oral viscosity, firmness, and mouth coating sensations (Foegeding 2006; Lee and Lucey 2006).The equivalent measure for a foam system is yield stress, which indicates the force at which the foam stops acting like a viscoelastic solid and begins to flow. Since an aerated gel may have both gel-like and foam-like qualities we analyzed which of the measured characteristics had an effect on either $\mathrm{G}^{\prime}$ or yield stress (Table 2).

Table 2 Viscoelastic Properties of Aerated Gels

\begin{tabular}{|c|c|c|c|c|c|c|}
\hline Type & $\begin{array}{c}\text { Final PS } \\
\text { Concentration }\end{array}$ & $\begin{array}{c}\text { Gelation } \\
\text { time (s) }\end{array}$ & $\begin{array}{c}\text { Gel Strength } \\
(\mathrm{g})\end{array}$ & Final G' (Pa) & $\begin{array}{c}\text { Percent } \\
\text { Overrun }\end{array}$ & $\begin{array}{c}\text { Yield Stress } \\
(\mathrm{Pa})\end{array}$ \\
\hline WPI-LM12 & 0.315 & $495 \pm 23$ & $235 \pm 7$ & $10,550 \pm 353$ & $30.61 \pm 2.88$ & $1550 \pm 14$ \\
\hline WPI-HM D & 0.315 & $415 \pm 20$ & $203 \pm 11$ & $7,395 \pm 223$ & $67.37 \pm 0.53$ & $468 \pm 59$ \\
\hline WPI-Guar & 0.315 & $444 \pm 2$ & $310 \pm 11$ & $8,215 \pm 21$ & $75.07 \pm 0.79$ & $1188 \pm 28$ \\
\hline
\end{tabular}

Values are means $\pm S D$

There were significant differences in the aerated gels final $G^{\prime}(P=0.0021)$ by polysaccharide type. WPI-LM12 had the highest G' followed by WPI-Guar and WPI-HM D. Although gel strength and $\mathrm{G}^{\prime}$ are both measurements of gel firmness, no relationship was found between gel strength and $G^{\prime}(P=0.96)$. This is likely because the gel strength measurement was done on non-aerated samples and $\mathrm{G}^{\prime}$ on aerated gels so they do not follow the same trends. When gel strength and overrun are used together in a regression equation, they are strongly predictive of final $\mathrm{G}^{\prime}\left(\mathrm{P}=0.0011, \mathrm{R}^{2}=0.99\right)$.

$$
G^{\prime}=9822-74.3 \text { (Overrun) + 12.8(Gel Strength) }
$$

Samples with lower overrun or higher gel strength have higher G'. Both the strength and elasticity of the gel network and the air volume entrapped in the gel 
contribute to the mouthfeel properties of $\mathrm{G}^{\prime}$. Complexes made with high charge density polysaccharides will have higher gel strength due to the increased protein-protein interactions in the gel network. These increased protein-protein interactions contribute to increased G' (Zhang and others 2014). They can also contribute to increase solution viscosity prior to gelation which, as has been previously discussed, limits overrun. Additionally, higher overrun limits $\mathrm{G}^{\prime}$ because the air bubbles make the gel network less dense and less able to elastically stretch in response to force. The WPI-Guar sample did not follow this trend as it experienced phase separation which can artificially inflate gel strength results.

The different polysaccharides had significantly different aerated gel yield stress $(P=0.017)$. As it is similar to $G^{\prime}$, it is expected that high overrun will be associated with lower yield stress due to alterations of the gel network and that increased gel strength will relate to increased yield stress. Individually, there was no relationship between either gel strength and yield stress $(P=0.39)$ or overrun and yield stress $(P=0.19)$. However, when considered together, gel strength and overrun are predictive of sample yield stress $\left(P=0.041, R^{2}=0.88\right)$ with higher gel strength and lower overrun associated with higher yield stress.

$$
\text { Yield Stress }=351-21.5(\text { Overrun })+7.86(\text { Gel Strength })
$$

The yield stress was highest for the WPI-LM-12 samples (Table 2). In these, like in the case of $\mathrm{G}^{\prime}$, the increased protein-protein interactions of the complex led to increased durability of the foam structure. The yield stress values for WPI-Guar were 
between those of WPI-LM12 and WPI-HM D. This may be due to the lower viscosity and higher overrun of guar gum at the selected concentration.

\subsubsection{Lactic Acid Bacteria Gelation}

The primary acidulation agent in this study is glucono- $\delta$-lactone (GDL); it has consistent results with a fast initial pH decrease. However, the primary application of dairy aerated gels is for whipped yogurts. Milk fermentation with lactic acid bacteria $(L A B)$ is a slower process than with GDL. Although the final $\mathrm{pH}$ reached was the same in 24 hours, fermentation with lactic acid bacteria starts out slowly and then $\mathrm{pH}$ begins to drop at a steady pace. Its known that both the final $\mathrm{pH}$ and the rate of $\mathrm{pH}$ change have a significant effect on gel properties (Jumah and others 2001). Acidification with bacteria also produces several metabolic byproducts such as exopolysaccharides which will effect texture properties (Marle and Zoon 1995; Lucey and others 1998). To confirm that the results on stability from this study could be applied to fermented dairy aerated gels, we repeated the drainage study on samples acidulated with LAB to study how stability is effected by acidulation rate. 


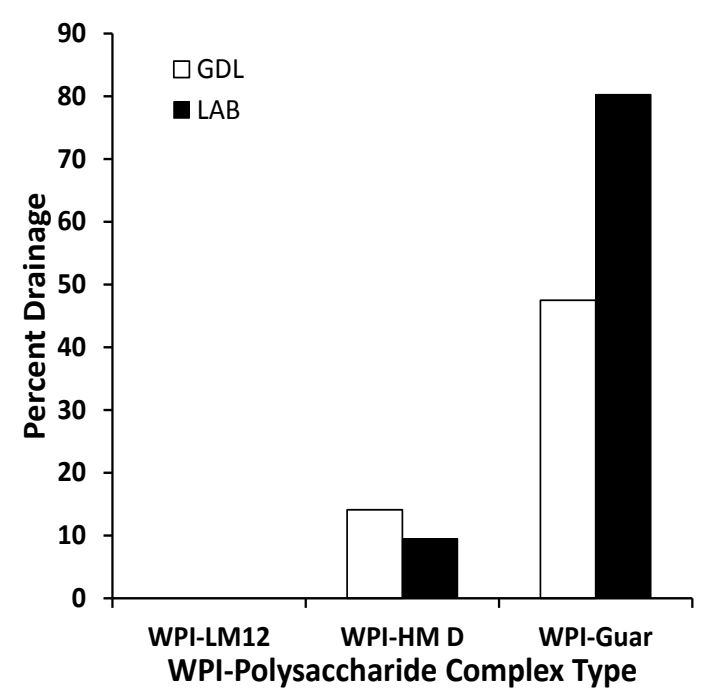

Figure 8 Percent drainage of the aerated gels at polysaccharide concentration $0.315 \%$ with two acidulation methods; GDL (white) and Lactic Acid Bacteria (black)

Drainage results with the two acidulation agents were significantly different $(\mathrm{P}<0.0001)$. Overall the lactic acid bacteria samples had higher percent drainage than the GDL samples ( $P=0.0076$ ) (Figure 8 ). The stability of aerated gels acidified with yogurt bacterial cultures followed the same trend of increased stability with higher charged polysaccharides. Only the $0.315 \% \mathrm{LM}-12$ pectin solution had zero drainage. The slower acidulation rate did not affect drainage for HM-D, but the guar gum drainage nearly doubled. One explanation is that at these concentrations the viscosity of the HM-D solution is $415.8 \pm 32.8 \mathrm{mPa}$.s and for guar gum it is $26.45 \pm 3.21 \mathrm{mPa}$.s, so the higher viscosity of the HM-D sample may have protected it from increased drainage during a longer gelation time. 


\subsection{Conclusion}

This study demonstrates that stable aerated dairy gels can be created by utilizing WPI-polysaccharide complexes. Results confirm that both polysaccharide concentration and electrostatic charge density have significant effect on the stability and final properties of aerated gels. It is possible to create stable aerated gels with WPIpolysaccharide complexes by adjusting the polysaccharide type and use level. High charge density polysaccharides, at concentrations that provide adequate viscosity, are needed to achieve stability while also maintaining solution overrun capabilities. This can be applied to dairy based gels set by acid or calcium such as yogurt or mousses where aeration can increase their appeal by creating novel textures and reducing calories by volume. 


\title{
CHAPTER 4 MANUSCRIPT 2: Carrageenan
}

\author{
Manuscript to be Submitted to the Journal of Dairy Science
}

\subsection{Abstract}

Whey protein isolate (WPI, 8\% protein) was heated with three carrageenans of differing charge density, $\lambda$ - (high charge), l- (medium charge), and $\mathrm{k}$ - (low charge), at multiple concentration ratios at $\mathrm{pH} 7$ and then mixed with heated skim milk powder $(8 \%$ protein). To form aerated gels, $2 \%$ glucono- $\delta$-lactone (GDL) was added and foam was generated by whipping with a handheld frother. The foam set into a gel as the GDL acidified to a final pH of 4.2. The aerated gels were evaluated for stability, overrun, and rheological properties.

Overall stability was indicated by measuring liquid separation drained from the foam before it set as a gel. Stable aerated gels could not be created without heated WPI-carrageenan complexes. Increasing carrageenan concentration increased the stability as expected by mechanism of increasing the viscosity of the solution. Increasing viscosity was also associated with decreased foam overrun; however, this relationship was limited in high charge density systems. Stability of aerated gels was achieved through both the electrostatic interactions between WPI and high charge density carrageenan and interactions between $\mathrm{k}$-carrageenan with casein micelles. The textural attribute, yield stress, can be predicted using a multiple regression model using gel strength of non-aerated gel and the aerated overrun. 


\subsection{Introduction}

Aerated gels can be described as foods that combine both the properties of foams and gels. Like a foam, the added bubbles in an aerated gel introduce a novelty factor, can improve creamy or light texture and have reduced calories per volume (Campbell and Mougeot 1999; Lau and Dickinson 2005; Osterholt and others 2007). However, compared to many foams, aerated gels have high protein content, a longer shelf life and possibly increased satiation capabilities due to their gel-like nature (Schmidt and Morris 1984; Keogh and O'Kennedy 1998; McCrickerd and others 2012). Compared to either foams or gels, very little research has been done on aerated gels and factors affecting their stability and textural properties.

Whey protein, a valuable byproduct of the cheese making industry, has been extensively studied for its functional properties in foam and gel systems. In particular, heated whey protein polymers are well known to improve the stability of foams and gels due to their amphiphilic properties, aggregate size, and protein-protein interactions (Bikker and others 2000; Vardhanabhuti 2000; Foegeding and others 2002; Tosi and others 2007; Donato and Guyomarc'h 2009).

More recent research on whey protein functionality has focused its interactions with charged polysaccharides. Typically in a mixed system with two charged polymers such as whey proteins and polysaccharides, they will either segregate into a bilayer system, or attract and form insoluble aggregates (de Kruif and Tuinier 2001). However, when solutions of native whey protein and polysaccharides are heated together at a $\mathrm{pH}$ above the protein isoelectric point (pl), the positive patches of the protein that are 
exposed during unfolding are able to interact with the negatively charged polysaccharides to form a heated soluble complex. A study of whey protein foam properties found that heating the whey protein with $\lambda$-carrageenan led to increased foamability and increased drainage $1 / 5$ life. These changes are attributed to proteinpolysaccharide interactions improving elasticity and film viscosity of the foam (Wang 2013).

Whey protein-polysaccharide heated soluble complexes have also been applied to acid-induced gelation. Interactions between the polysaccharides and the proteins can alter gel properties and microstructure (Cavallieri and Cunha 2009). In studies with pectin, complex formation at $\mathrm{pH} 7$ and use of the highest charge density pectin were able to improve acid induced gel strength and water holding capacity (Zhang and others 2014; Zhang and Vardhanabhuti 2014).

Since whey proteins are capable of stabilizing both foams and gels, they are a good starting point for investigating stabilization of aerated gels. In a previous study, heated complexes made with whey protein and pectin were evaluated for their effect on aerated gel properties. It was found that increasing polysaccharide concentration in the complex led to increased viscosity of the non-aerated solution, decreased overrun after aeration, and decreased liquid drainage from the aerated gel. High charge density pectin was able to produce a stable drainage-free gel with a smaller increase in solution viscosity than the low charge density pectin, allowing for a stable aerated gel with a higher overrun ( $\mathrm{O}^{\prime} \mathrm{Chiu}$ and Vardhanabhuti, manuscript in preparation). It is unknown if 
other polysaccharides will follow similar trends of concentration and charge density in an aerated gel system.

Similar to pectins, carrageenans are available in a range of charge densities. They can be divided into three classes based on the number of sulfate groups per disaccharide, $\mathrm{k}$-carrageenan has one, $\mathrm{l}$-carrageenan has two, and $\lambda$-carrageenan has three. The number of sulfate groups controls how negatively charged the polysaccharide molecules are and effects their conformations differently under different temperature and ionic conditions (Bourriot and others 1999a; Langendorff and others 2000).

Carrageenan could possibly have even greater application in dairy aerated gels than pectin due to its ability to interact with casein micelles. The most negatively charged, $\lambda$-carrageenan, has a loose coil structure. It has been shown to adhere to casein micelles at 60 ㅇ $\mathrm{C}$ when other carrageenans do not, due to electrostatic forces (Langendorff and others 2000). When present in a mixed solution that is heated above $80 \circ \mathrm{C}$ then cooled past the transition temperature $(\sim 49 \circ \mathrm{C})$ the $\mathrm{K}$-carrageenan and $\mathrm{t}-$ carrageenan will change from a coil structure to a tighter more organized helix structure. When they do so, the charge density is increased to a high enough level to allow for adherence to the micelle surface. (Langendorff and others 2000; de Kruif and Tuinier 2001). Additional evidence suggests that the conformation of $\mathrm{k}$-carrageenan in its helix form allows it to uniquely interact with $\mathrm{k}$-casein on the surface of micelles to form micelle bridges in a mixed solution (Bourriot and others 1999a; Thaiudom and Goff 2003; Spagnuolo and others 2005; Ji and others 2008). 
The objective of this study was to investigate the effect of heated whey proteincarrageenan complex on low pH aerated skim milk gel. The effects of carrageenan types (different charge density) and concentration were studied. A greater understanding of how heated complex addition can be used to maintain product stability while manipulating properties such as overrun and yield stress will allow the dairy industry to create successful novel-textured products.

\subsection{Materials and methods}

\subsubsection{Materials}

Whey Protein Isolate (WPI) containing $93.4 \%$ protein was donated by Davisco Foods Intl. (Le Sueur, MN). Skim milk powder (SMP) containing 35\% protein was obtained from a bulk manufacturer. Polysaccharides (PS) consisted of $\mathrm{k}$-carrageenan $(\mathrm{KC})$, l-carrageenan ( $\mathrm{LC})$, and $\lambda$-carrageenan $(\lambda C)$ (FMC Biopolymer, Philadelphia, PA). Acidulation was achieved with either glucono-- $\delta$-lactone (GDL) provided by Sigma-Aldrich Corp. (St. Louis, MO) or yogurt cultures containing Streptococcus thermophilus and Lactobacillus bulgaricus provided by DuPont Danisco (Madison, WI). All other chemicals are of analytical grade.

\subsubsection{Biopolymer Preparation}

WPI stock solution (15\% protein $\mathrm{w} / \mathrm{w}$ ) was formed by dissolving protein powder in deionized (DI) water and slowly stirring at room temperature for $\geq 4$ hours for complete hydration. A dispersion of SMP (23.5\% solids, $8 \%$ protein $w / w)$ was made in a similar manner. After full hydration, the SMP was held in a $99.9{ }^{\circ} \mathrm{C}$ water bath until it reached $>90^{\circ} \mathrm{C}$ for 5 minutes. Then, it was cooled in an ice bath and held at $5 \circ \mathrm{C}$ prior to 
use. Carrageenans $(1 \% \mathrm{w} / \mathrm{w})$ were stirred on a hotplate to a temperature above their transition temperature $\left(60^{\circ} \mathrm{C}\right)$ and added to WPI solutions before cooling and transitioning to helical structure, per manufacturer's directions.

\subsubsection{Formation of Heated WPI-PS Complexes}

WPI and polysaccharides were mixed at appropriate amount and their $\mathrm{pH}$ was adjusted to 7.0 with 0.1 and $0.01 \mathrm{~N} \mathrm{NaOH}$. DI water was added such that the final protein concentration was $8 \%(\mathrm{w} / \mathrm{w})$ and polysaccharide concentration ranging from 0 to $0.24 \%(w / w)$. The mixtures were gently stirred at room temperature for $2 \mathrm{~h}$ before being heated in a temperature-controlled water bath at $85^{\circ} \mathrm{C}$ for $30 \mathrm{~min}$ and cooled in an ice bath. The cooled WPI-PS complexes were then mixed with the heated skim milk in a 60:40 weight ratio. Deionized water was added to all the samples to produce the final protein concentration of $7 \%$. The finished samples were stored at $50 \mathrm{C}$ overnight prior to testing for complete interaction between protein and polysaccharide.

\subsubsection{Viscosity Measurement}

Viscosity measurement was conducted on polysaccharide as well as mixed systems of SMP and heated WPI-PS complex solutions. Polysaccharide solutions were prepared from the stock solutions, diluted with $\mathrm{DI}$ water and $\mathrm{pH}$ adjusted to 7.0.

Viscosity was measured on a Kinexus Pro rheometer (Malvern Instruments Ltd, Worcestershire, UK) using a $65 \mathrm{~mm}$ diameter lower plate and $40 \mathrm{~mm}$ diameter 4 을 cone upper geometry with $0.15 \mathrm{~mm}$ gap. Shear rate was increased from 0.1 to $100 \mathrm{sec}^{-1}$ at 25 ㅇ C 


\subsubsection{Acid-Induced Gelation}

GDL was added to the treatments at $2 \% \mathrm{w} / \mathrm{w}$ (GDL/total) for all samples except the skim milk control which required $3.5 \% \mathrm{w} / \mathrm{w}$ to reach the same $\mathrm{pH}$ of $4.5 \pm 0.1$ after $24 \mathrm{~h}$ of storage at $5 \circ \mathrm{C}$. The mixtures were gently stirred for $30 \mathrm{~s}$ and then three $1.5 \mathrm{~mL}$ aliquots were transferred to microcentrifuge tubes for water holding capacity measurement. Samples were covered with parafilm and left overnight at 4 으. All testing was completed within $24 \pm 1$ hours of GDL addition.

Gel Texture Analysis. Gel samples were removed from the fridge and allowed to equilibrate to room temperature for two hours prior to testing. A TA-HDi Texture Analyzer (Texture Technologies Corp., Scarsdale, N.Y.,) equipped with a $5 \mathrm{~kg}$ load cell operated at a test speed of $10 \mathrm{~mm} / \mathrm{s}$ measured force in compression with a $13 \mathrm{~mm}$ diameter stainless steel probe. The penetration distance was fixed to $10 \%$ of the original gel thickness $(30 \mathrm{~mm})$ and was held for $300 \mathrm{~s}$. The peak force for each sample was recorded.

Water Holding Capacity. Gel samples (1.5 g) in centrifuge tubes were removed from the fridge and allowed to equilibrate to room temperature for two hours prior to testing. Gelled samples were placed in a micro-centrifuge operating at 10,000 RPM $(9,037 \mathrm{~g})$ for 10 minutes. The free liquid was removed from the top of each sample by micropipette and weighed in $\mathrm{mg}$. The measurements were completed in triplicate. The percent water holding capacity $(\mathrm{WHC})$ was calculated from the recorded weight of free liquid with the equation: $\frac{(1500-\text { recorded wt in } \mathrm{mg})}{1500} \times 100$ 


\subsubsection{Formation of aerated gel}

For consistent foaming conditions, foam samples were created by placing $40 \mathrm{~g}$ of each test treatment into a $250 \mathrm{~mL}$ beaker. GDL was added (28.6 mg GDL per g of protein) and the samples were stirred quickly for 30 seconds to dissolve the crystals. Immediately after GDL addition, the samples were whipped for 2 minutes with a hand held Aerolatte ${ }^{\circledR}$ frothing wand (Aerolatte Ltd, Radlett, UK) connected to a 3.7 volt, 0.35 amp power adapter for consistent power supply. All foam property measurements were taken immediately after aeration.

Drainage. To measure the degree of liquid drainage from the foam before gelation set in, the aerated solution was poured into a $15 \mathrm{~mL}$ centrifuge tube until it was level with the top $(15.75 \mathrm{ml}$ total volume). The weight of the foam in the tube was recorded. After 15 minutes, the aerated solution had gelled and the volume of liquid which had drained from the foam and collected at the bottom of the tube was recorded. The percent drainage was calculated using the equation:

$\frac{\mathrm{mL} \text { of drained liquid } \mathrm{x} \text { density }}{\text { total weight of foam in tube }} \times 100$

Overrun. Immediately after whipping, foam overrun was measured by gently transferring the foam into a pre-weighed $35 \mathrm{~mm}$ diameter $\times 10 \mathrm{~mm}$ petri dish $(9.62 \mathrm{~mL}$ total volume). The dish was filled to above the rim, then a metal spatula was used to level off the top of the foam for consistent volume before recording the weight. The measurement was completed in triplicate. The percent overrun was calculated using the equation: $\frac{(9.62 \times \text { density })-\text { recorded weight }}{\text { recorded weight }} \times 100$ 


\subsubsection{Viscoelastic Properties}

Further study of small scale deformation of the aerated gels was conducted on samples containing $0.126 \%$ polysaccharides. This concentration was chosen because it forms a stable aerated gel for all samples. Samples with lower polysaccharide concentrations were excluded because the liquid drainage from the foam created a nonhomogenous structure.

Viscoelastic properties of aerated gels. Immediately after whipping, foams were gently loaded into the Kinexus Pro Rheometer with a plate and plate geometry $(50 \mathrm{~mm}$ upper plate) with a $1 \mathrm{~mm}$ loading gap. The excess foams were gently removed and the solvent trap was used to prevent sample drying. The development of elastic modulus $\left(G^{\prime}\right)$ was monitored in the linear region ( $0.5 \%$ strain) at a constant frequency of $1 \mathrm{~Hz}$ at 25ㅇ C for 6 hours. Sample gelation time was determined by recording the point where the change in $\mathrm{G}^{\prime}$ during gel formation is discernable from background noise as defined by Horne (1999). G' at 6 hours after GDL addition was chosen to represent the final $\mathrm{G}^{\prime}$.

Yield Stress. After whipping, foam was gently loaded on the Kinexus Pro Rheometer using $40 \mathrm{~mm}$ serrated upper and lower plates with a $1 \mathrm{~mm}$ gap. The excess foams were gently removed and the solvent trap was used to prevent sample drying. Aerated gel was allowed to form in situ for $2 \mathrm{hr}$. A single shear rate of 0.01 was applied for 10 minutes. Yield stress was defined as the peak recorded shear stress $(\sigma)$.

\subsubsection{Lactic Acid Bacteria Gelation}

Yogurt starter cultures containing Streptococcus thermophilus and Lactobacillus bulgaricus were added at $0.01 \%$ concentration to the sample solution as recommended 
by the manufacturer. After 30 minutes of gentle stirring at room temperature, the samples were foamed, poured into $15 \mathrm{~mL}$ centrifuge tubes, and incubated at $42^{\circ} \mathrm{C}$ for 6 hours. After incubation, drainage measurements were conducted in the same manner as for the GDL samples. The sample pH was also recorded.

\subsubsection{Statistical Analysis}

Statistical analysis was completed with SAS version 9.3 (SAS Institute Inc., Cary, IN). All values are means \pm SD. Statistical differences were analyzed using PROC GLM for ANOVA followed by the Tukey-Kramer test, and for regression analysis. P values $<0.05$ were considered statistically significant. All statistical analysis was done on at least 2 replications.

\subsection{Results and discussion}

The formation of the aerated gels in this study was done with a handheld frother, a relatively new method that is also found in a previous study on lactoglobulin and casein foam coarsening (Blijdenstein and others 2010). Preliminary tests of overrun and drainage on SMP with heated WPI-polysaccharide complexes showed that the test repeatability was good if both the time between sample mixing and testing, and the time between GDL addition and testing, were controlled (results not shown).

\subsubsection{Aerated Gel Overrun}

Overrun of aerated gels ranged from $51.0 \pm 5.1$ to $87.1 \pm 7.2$ for SMP gels with

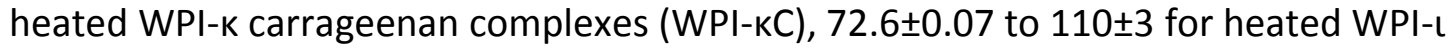
carrageenan complexes (WPI-IC), and $60.6 \pm 0.8$ to $87.1 \pm 5.3$ for heated WPI- $\lambda$ carrageenan complexes (WPI- $\lambda \mathrm{C})$. The trend for overrun was that it decreased 
significantly as polysaccharide concentration increased ( $P=0.0017$ ) (Figure $9 A)$. This is expected because the presence of polysaccharide leads to increased viscosity of prefoam solution and thus limits air incorporation during frothing. When overrun values are separated by polysaccharide type it can be seen that the overrun for the WPI-KC decreased with concentration linearly, while the WPI-LC and WPI- $\lambda$ C samples experienced a slight increase in overrun at the second polysaccharide concentration (0.84\%), despite having an overall decreasing trend (Figure 9B).

Several studies have reported the negative correlation between overrun of protein foams and the viscosity of pre-foam solutions at the shear rate corresponding to whipping shear rate (Campbell and Mougeot 1999; Mott and others 1999; Pintor and Totosaus 2012). Since the exact shear rate of the Aerolatte ${ }^{\circledR}$ frother is not known, we have analyzed the relationship between the overrun and the viscosity at shear rates of 50,80 , and $100 \mathrm{sec}^{-1}$. The same relationships were found at all three shear rates. There were significant differences in the high shear viscosity for each of the polysaccharide types and high shear viscosity was found to be a strong predictor of foam overrun $(P=0.032)$ (Figure 10A). Viscosity values at shear rate $100 \mathrm{sec}^{-1}$ were chosen to be reported in this article's tables and figures.

Again, as was seen with overrun and concentration, the $0.084 \%$ WPI-LC and WPI$\lambda C$ samples experience an increase in overrun despite also increasing in viscosity (Figure 10B). This effect has been seen before in a study of WPI- $\lambda$ C complex foamability. Overrun of heated WPI- $\lambda C$ also increased at low $\lambda C$ concentration (Wang 2013). It was suggested that interaction between protein and polysaccharide during heating at $\mathrm{pH}>$ 
pl resulted in stronger interfacial film and increased the amount of adsorbed protein at the interface, leading to increased overrun. Similar reason could likely explain the observed overrun at $0.084 \% \mathrm{LC}$ and $\lambda \mathrm{C}$. At higher polysaccharide concentration, the effect of viscosity dominated and the overrun decreased. WPI-KC did not follow this trend. WPI-pectin complex based aerated gels behaved similarly to WPI-KC with a linear decrease in overrun as concentration increased $\left(\mathrm{O}^{\prime} \mathrm{Chiu}\right.$ and Vardhanabhuti, manuscript in preparation). One explanation for this is $\lambda C$ and $\mathrm{IC}$ were more highly charged and had higher degree of interaction with WPI. 

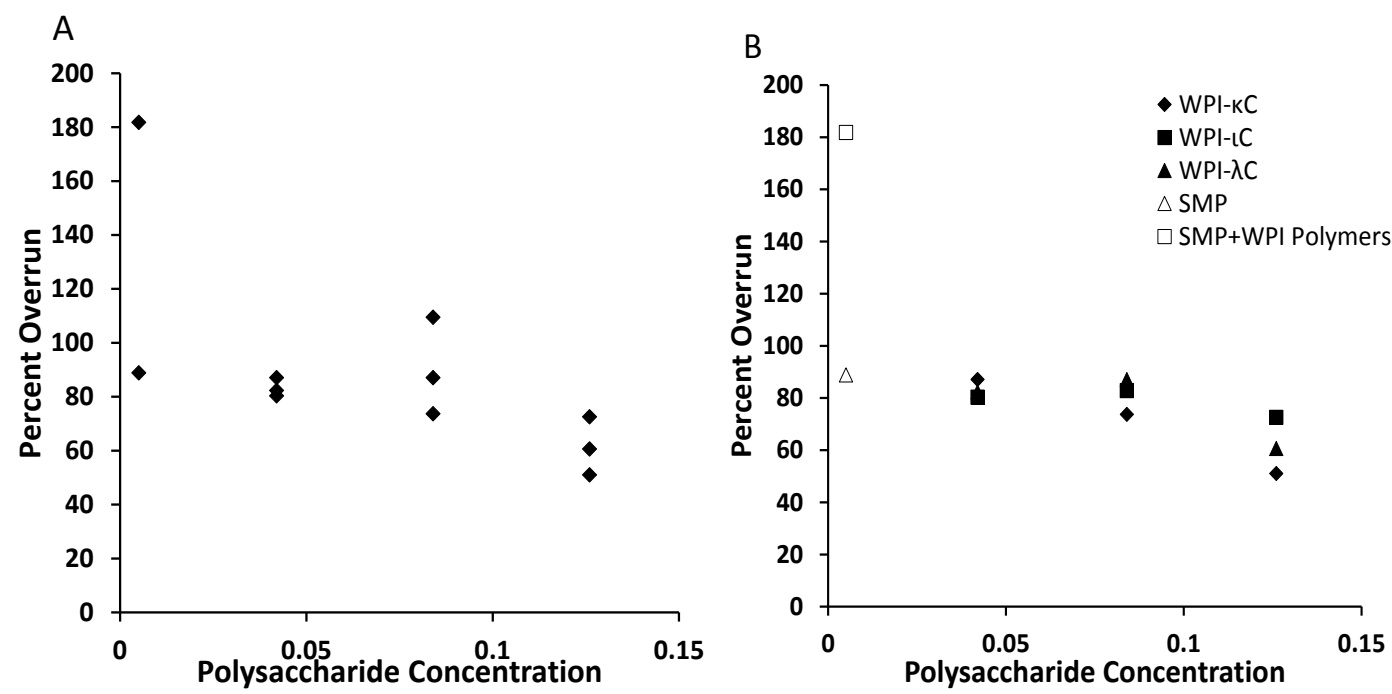

Figure 9 Percent overrun of aerated gels with different polysaccharide concentrations of A) all samples B) samples organized by type
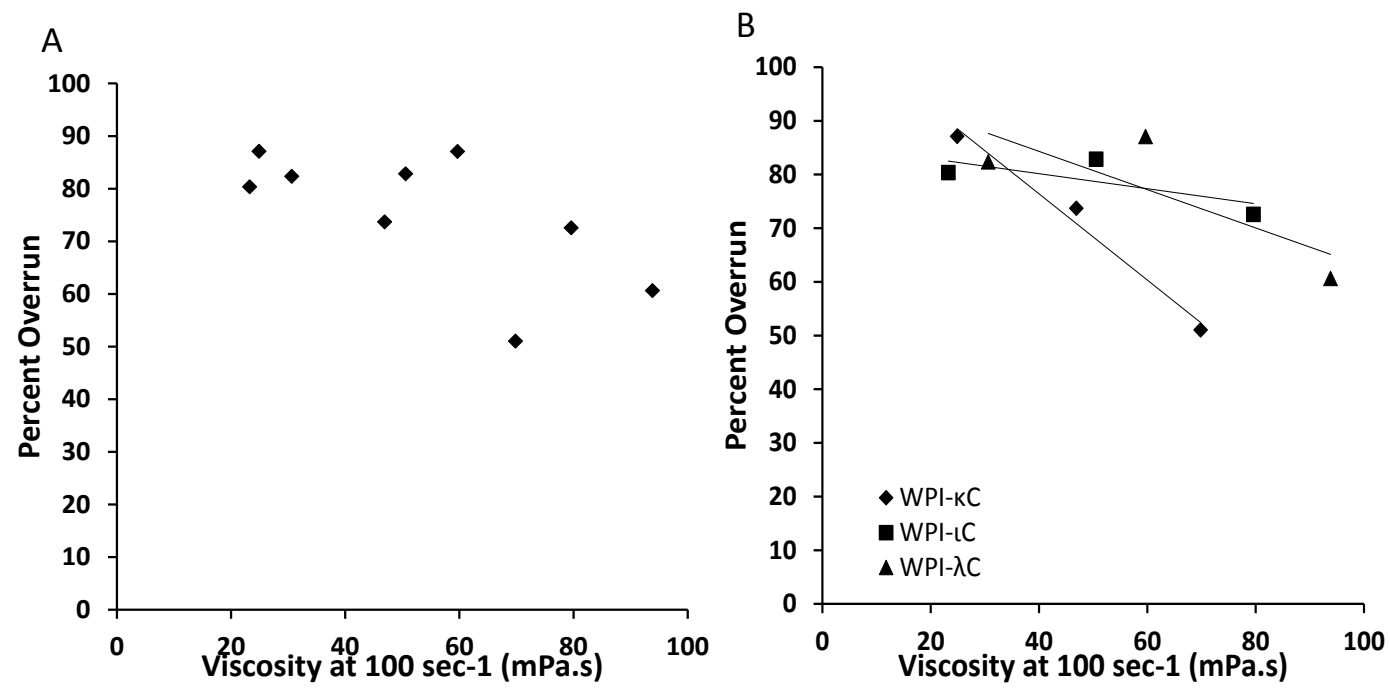

Figure 10 Percent overrun of aerated gels versus viscosity at $100 \mathrm{sec}^{-1}$ for A) all samples

B) samples organized by type 


\subsubsection{Stability of Aerated Gels}

The most problematic defect in aerated gels is drainage of liquid from the foam before gelation occurs resulting in a non-uniform product (Tomczynska-Mleko 2013). In samples with no drainage, air bubbles can be seen spread evenly throughout the gel network. When drainage occurs, a two phase system forms with the air bubbles creaming at the top of the container and a distinct gel layer with no air at the bottom. This is different from traditional foams in which drainage is generally measured as the time it takes for half of the foam by weight to drain from its container or for half of the height of the foam to collapse within a column (Lau and Dickinson 2005). Collapsing of the foam resulting in a decrease in volume was only seen in the least stable SMP control samples. Here, stability is expressed as percent drainage by weight to control for the change in total aerated gel weight at the same volume with different overruns.

Without heated complexes, SMP alone could not form stable aerated gels; drainage began immediately after aeration. Stable aerated gel was also not achieved when heated whey proteins (WPI-polymers) were used. Previous research on carrageenan milk solutions found that $\mathrm{IC}$ and $\lambda \mathrm{C}$ dissolved in milk at concentrations above $0.1-0.2 \%$ led to depletion flocculation related separation of milk proteins. Kappa carrageenan samples and lower concentrations of other carrageenans were able to form a gel network. However only casein and carrageenans become cross-linked in this process so the gels experienced separation and released liquid whey (Langendorff and others 1997; Shchipunov and Chesnokov 2003). By forming heated WPI-carrageenan complex before adding to SMP, the stable system can be created with no drainage or 
phase separation. Reductions in drainage were achieved when $60 \%$ of SMP was replaced with WPI-carrageenan complex. Stability was significantly affected by carrageenan concentration $(P<0.0001)$ and the type of carrageenans $(P<0.0001)$. Increasing carrageenan concentration resulted in a decrease in percent drainage across all samples (Figure 11A). The percent drainage for WPI-kC ranged from $0 \pm 0$ to $31.6 \pm 0.9$, from $0 \pm 0$ to $56.3 \pm 6.6$ for WPI- $\mathrm{LC}$ and from $0 \pm 0$ to $47.0 \pm 0.1$ for WPI- $\lambda$ C. Complete stability (no drainage) was achieved at $0.084 \%$ for WPI-KC and $0.126 \%$ for all carrageenans.

When percent drainage versus concentration was separated by type, it is apparent that the three carrageenan types each have a different effect (Figure 11B). The decrease in drainage seen in high charge density WPI- $\lambda$ C is linear, the trend line has a slope of $-559\left(R^{2}=0.99\right)$. The relationship for WPI- $\mathrm{LC}$ is less linear with a slope of -668 $\left(R^{2}=0.86\right)$. At lower concentrations the higher charge of the $\lambda C$ in the WPI complex is better able to prevent drainage of aerated gels. At higher concentrations, more $\mathrm{\imath C}$ is available to form helices which can stabilize the aerated gel better than $\mathrm{IC}$ in random coil configuration (Langendorff and others 1999). The trend line for drainage of WPI- KC is not useful because two of the samples have a drainage of 0 . Despite having the least electrostatic charge interactions within the WPI complex, $\mathrm{kC}$ was able to stabilize aerated gel drainage at both the $0.84 \%$ and $0.126 \%$ concentration. Previous research on $\mathrm{KC}$ gelation with milk proteins found that it interacts favorably with the micelle surface and at concentrations above $0.05 \%$ can form an entangled polymer network with casein that resists separation (Thaiudom and Goff 2003; Spagnuolo and others 2005). 

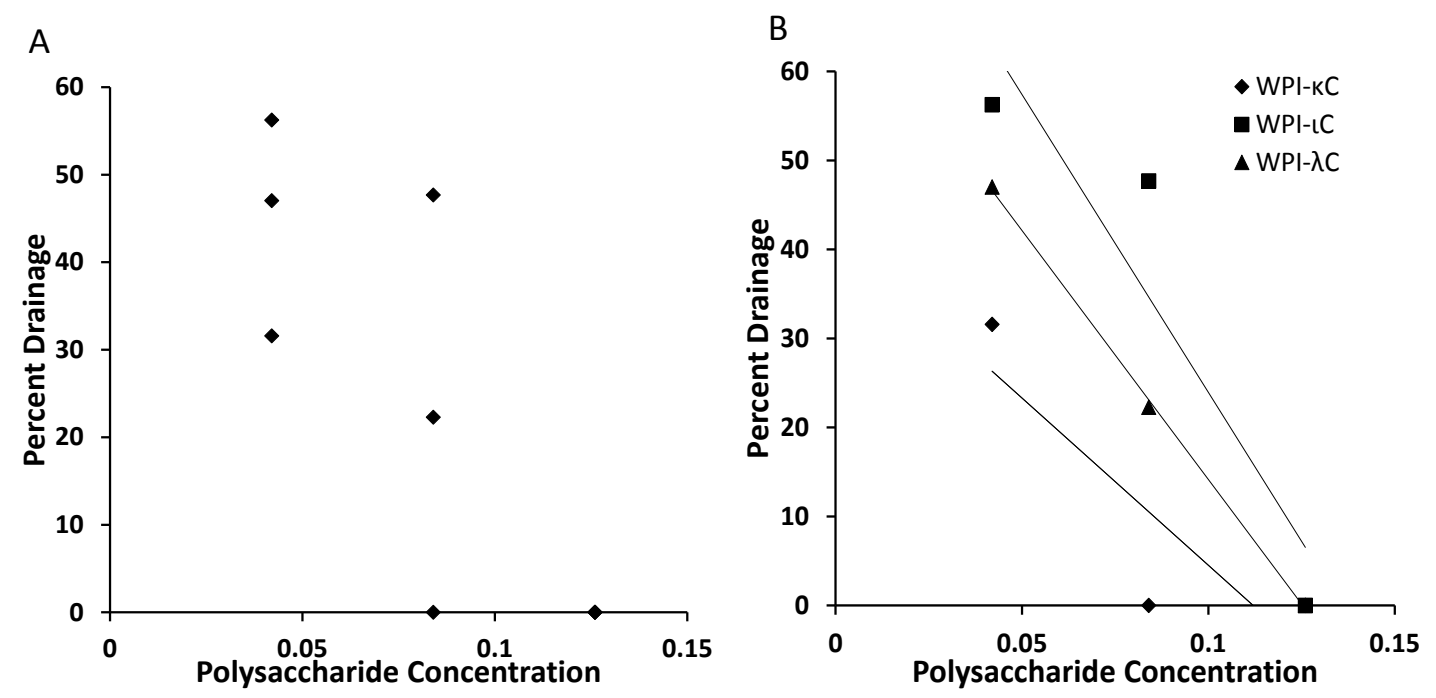

Figure 11 Percent drainage of aerated gels with different polysaccharide concentrations of $A$ ) all samples $B$ ) samples organized by type

Table 3 Effect of Viscosity on Drainage and Overrun

\begin{tabular}{|c|c|c|c|c|c|c|c|}
\hline Type & $\begin{array}{c}\text { Final PS } \\
\text { Concent- } \\
\text { ation }\end{array}$ & $\begin{array}{c}\text { Polysaccharide } \\
\text { Viscosity* } \\
\text { (mPa.s) }\end{array}$ & $\begin{array}{c}\text { WPI-PS } \\
\text { Complex } \\
\text { Viscosity* } \\
\text { (mPa.s) }\end{array}$ & $\begin{array}{c}\text { SMP-Cmpx } \\
\text { mixture } \\
\text { Viscosity* } \\
\text { (mPa.s) }\end{array}$ & $\begin{array}{c}\text { SMP-Cmpx } \\
\text { mixture } \\
\text { Viscosity** } \\
\text { (mPa.s) }\end{array}$ & $\begin{array}{c}\text { Percent } \\
\text { Overrun }\end{array}$ & $\begin{array}{c}\text { Percent } \\
\text { Drainage }\end{array}$ \\
\hline WPI-KC & 0.042 & $2.72 \pm 0.17$ & & $47.1 \pm 1.7$ & $24.9 \pm 1.7$ & $87.1 \pm 7.2$ & $31.6 \pm 0.9$ \\
WPI-LC & 0.042 & $6.10 \pm 0.13$ & & $41.7 \pm 5.0$ & $23.2 \pm 0.4$ & $80.4 \pm 1.5$ & $56.3 \pm 6.6$ \\
WPI- $\lambda C$ & 0.042 & $9.40 \pm 0.13$ & & $64.0 \pm 0.4$ & $30.6 \pm 0.8$ & $82.4 \pm 1.9$ & $47.0 \pm 0.1$ \\
\hline WPI-KC & 0.084 & $3.71 \pm 0.13$ & & $166 \pm 0$ & $46.9 \pm 0.7$ & $73.7 \pm 2.1$ & $0 \pm 0$ \\
WPI-LC & 0.084 & $11.7 \pm 0.1$ & & $153 \pm 18.2$ & $50.6 \pm 0.9$ & $82.9 \pm 7.0$ & $47.7 \pm 2.2$ \\
WPI- $\lambda C$ & 0.084 & $16.0 \pm 0.6$ & & $191 \pm 6$ & $59.7 \pm 3.7$ & $87.1 \pm 5.3$ & $22.3 \pm 1.7$ \\
\hline WPI-KC & 0.126 & $4.42 \pm 0.05$ & $28.0 \pm 0.9$ & $188 \pm 2$ & $69.8 \pm 1.1$ & $46.2 \pm 1.8$ & $0 \pm 0$ \\
WPI-LC & 0.126 & $18.2 \pm 1.0$ & $39.5 \pm 1.7$ & $291 \pm 15$ & $79.6 \pm 2.1$ & $72.6 \pm 0.1$ & $0 \pm 0$ \\
WPI- $\lambda C$ & 0.126 & $26.1 \pm 0.4$ & $130 \pm 2$ & $386 \pm 8$ & $93.8 \pm 7.0$ & $60.6 \pm 0.8$ & $0 \pm 0$ \\
\hline
\end{tabular}

Values are means \pm SD

* Viscosity measured at $8 \mathrm{sec}^{-1}$ shear rate

** Viscosity measured at $100 \mathrm{sec}^{-1}$ shear rate 
As viscosity is influential on overrun and stability outcomes, the relationship between viscosity and charge density was further investigated (Table 3). Viscosities were measured of the polysaccharides in DI water at the same concentration as they were in the aerated gels, of the WPI-Polysaccharide complexes at $0.126 \%$ concentration, and the WPI-polysaccharide SMP mixture used to make the aerated gel at all concentrations. The trend for viscosity at $8 \mathrm{sec}^{-1}$ of the polysaccharide solutions shows that $\lambda C$ had the highest viscosity, followed by $\mathrm{IC}$ then $\mathrm{KC}$. When the polysaccharides were mixed with WPI and heated to form soluble complexes, the trend continues. However, the difference in viscosity between WPI- $\lambda C$ and the other samples is much greater. Increased protein-polymer interactions within WPI- $\lambda$ C, due to the high charge density of $\lambda C$, caused it to have more than three times the viscosity at the same polysaccharide concentration. A similar effect on solution viscosity has been seen with high charge density pectins (Zhang and Vardhanabhuti 2014)(O'Chiu and Vardhanabhuti, manuscript in preparation). The sample viscosities all increased when the complexes were mixed with heated SMP to make the solution used for the aerated gels. These solutions have a higher total solids content including $2.16 \%(\mathrm{w} / \mathrm{w})$ casein. The viscosity of WPI-KC in these samples may be raised due to increased interactions with casein.

Returning to the drainage results, the measurements of polysaccharide viscosity and solution viscosity were used to analyze the relationship of viscosity with drainage. Low shear viscosity of $8 \mathrm{sec}^{-1}$ was used to represent the shear force exerted by gravity. No relationship was found between the viscosity of just the polysaccharide being added to the system, and final sample stability (Figure 12). This indicates that aerated gel 
drainage cannot be improved simply by choosing a high viscosity polysaccharide. When the viscosity of the SMP-Complex mixture was plotted against percent drainage a negative relationship is seen $(P=0.0006)$ (Figure $13 \mathrm{~A})$. The effect of viscosity on drainage was not significantly different for each of the three polysaccharides (Figure 13B). Interestingly, this was not the result found for WPI-pectin complexes, in which higher charge density was significantly linked to decreasing drainage with a comparatively smaller increase in viscosity ( $\mathrm{O}^{\prime} \mathrm{Chiu}$ and Vardhanabhuti, manuscript in process). This is possibly because unlike pectins, $\mathrm{IC}$ and $\mathrm{KC}$ undergo increased helix formation as the concentration increases which explains why the trends for $\mathrm{IC}$ and $\mathrm{kC}$ are not particularly linear $\left(R^{2}=0.86\right.$ and $R^{2}=0.75$ respectively $)$. 


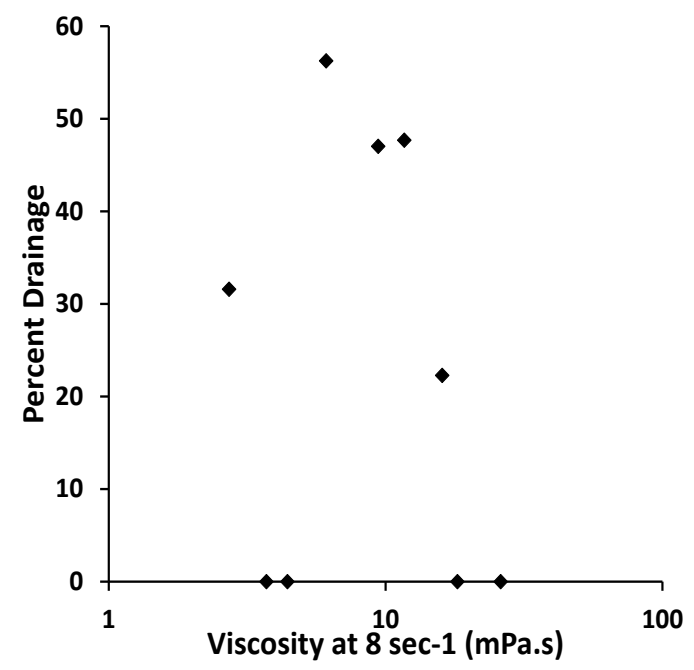

Figure 12 Percent drainage of aerated gel versus polysaccharide viscosity at 8 sec $^{-1}$

A

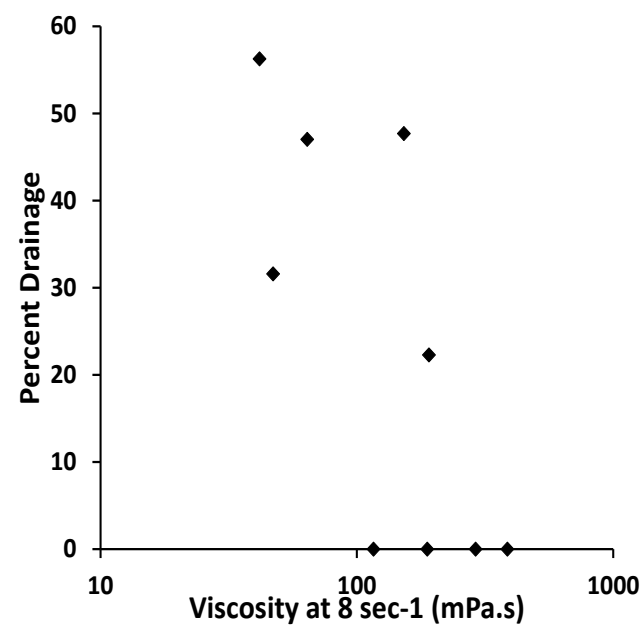

B

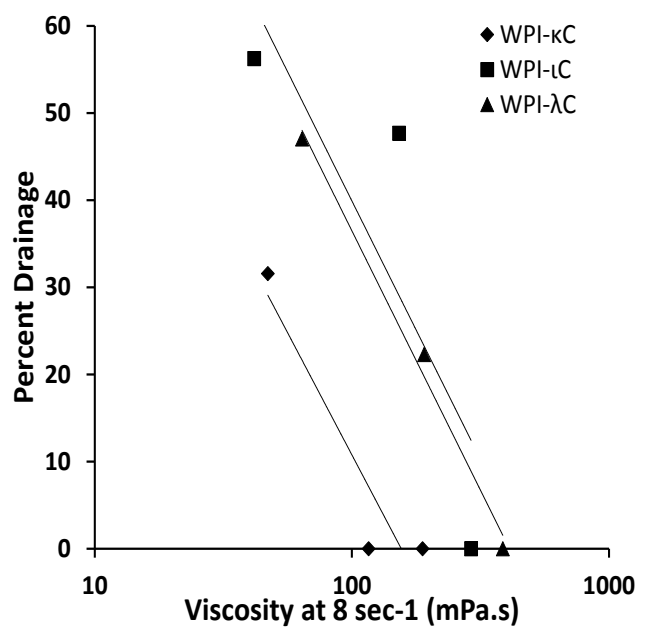

Figure 13 Percent drainage of aerated gel versus SMP-complex viscosity at $8 \sec ^{-1}$ for A) all samples B) samples organized by type 


\subsubsection{Water Holding Capacity}

There was no difference in the water holding capacity (WHC) for the WPIcarrageenan samples at any concentration (results not shown). The average measured WHC was $96.0 \% \pm 1.6$ for all samples.

As was discussed previously, poor water holding is a common problem in gels made with carrageenan heated with SMP(Langendorff and others 2000). As poor WHC is associated with high foam drainage and syneresis defects that shorten the shelf life of gels, it is crucial that WHC improvements be made (Keogh and O'Kennedy 1998). Therefore, it is very encouraging that the aerated gels made with WPI-carrageenan complex had such high WHC. Previous research established that heated WPIpolysaccharide complexes of any charge density have improved WHC when compared to gels made with WPI-polymers and polysaccharides at the same concentration (Zhang and Vardhanabhuti 2014). It is reasonable to conclude that the high WHC seen in the samples in this study is also related to WPI-polysaccharide complex formation. Samples that were stored for 14 days at 5 으 did not display any further syneresis in a preliminary shelf life trial (results not shown).

\subsubsection{Viscoelastic Properties}

The viscoelastic properties of protein based gels and foams are effected by acidulation rate and solution pH (Allen and others 2006; Zhang and others 2014). The samples all had a pH of $4.47 \pm 0.0324 \mathrm{~h}$ after GDL addition. Additionally no significant difference was found for gelation time of the three polysaccharide types though they did have a trend of faster gelation with lower charge density $(P=0.061)$. Regression 
analysis confirms that no relationship exists between gelation time and $G^{\prime}(P=0.99)$. In the absence of differences due to acidulation rate and solution $\mathrm{pH}$, we can assume that the measured rheological differences are due to differences in the three carrageenans. The elastic modulus $\left(\mathrm{G}^{\prime}\right)$ is a measure of gel deformation under shear forces and relates to gel oral viscosity, firmness, and mouth coating sensations (Foegeding 2006; Lee and Lucey 2006).The equivalent measure for a foam system is yield stress, which indicates the force at which the foam stops acting like a viscoelastic solid and begins to flow. Since an aerated gel may have both gel-like and foam-like qualities we analyzed which of the measured characteristics had an effect on either $G^{\prime}$ or yield stress (Table 4).

Table 4 Viscoelastic Properties of Aerated Gels

\begin{tabular}{|c|c|c|c|c|c|c|}
\hline Type & $\begin{array}{c}\text { Final PS } \\
\text { Concentration }\end{array}$ & $\begin{array}{c}\text { Gelation } \\
\text { time (s) }\end{array}$ & $\begin{array}{c}\text { Gel Strength } \\
(\mathrm{g})\end{array}$ & Final G' (Pa) & $\begin{array}{c}\text { Percent } \\
\text { Overrun }\end{array}$ & $\begin{array}{c}\text { Yield Stress } \\
(\mathrm{Pa})\end{array}$ \\
\hline WPI-KC & 0.126 & $505 \pm 11$ & $199 \pm 0$ & $7,435 \pm 1,251$ & $46.2 \pm 1.8$ & $1,665 \pm 7$ \\
\hline WPI-LC & 0.126 & $524 \pm 20$ & $108 \pm 1$ & $5,660 \pm 381$ & $72.6 \pm 0.1$ & $1,230 \pm 42$ \\
\hline WPI- $\lambda C$ & 0.126 & $530 \pm 13$ & $141 \pm 2$ & $6,965 \pm 643$ & $60.6 \pm 0.8$ & $1,031 \pm 55$ \\
\hline
\end{tabular}

Values are means \pm SD

ANOVA testing found no significant differences in $\mathrm{G}^{\prime}$ for each type of the aerated gels $(P=0.24)$. The trend was that WPI-KC had the highest $\mathrm{G}^{\prime}$ followed by WPI- $\lambda \mathrm{C}$ and WPI-ıC. The carrageenan types follow the same trend for the measurement of gel strength in compression where significant differences were found $(P<0.0001)$. Although gel strength and $\mathrm{G}^{\prime}$ are both measurements of firmness and mouth feel, there was no relationship between the two measurements $(P=0.12)$. This may be because the gel strength measurement was done on non-aerated samples and $\mathrm{G}^{\prime}$ on aerated gels. 
Aerated gel overrun did not have a significant effect on the measured $G^{\prime}(P=0.076)$ but did show a trend of lower overrun samples relating to higher $\mathrm{G}^{\prime}$. A regression equation of gel strength and overrun together found that they both contribute to the properties of $G^{\prime}\left(P=0.012 R^{2}=0.93\right)$.

$$
\mathrm{G}^{\prime}=24935-219(\text { Overrun})+31.98(\text { Gel Strength) }
$$

Previous rheological studies of aerated gels containing WPI-pectin complexes found that increased polysaccharide charge density led to increased $\mathrm{G}^{\prime}$ and gel strength, and that overrun and gel strength together were predictors of $\mathrm{G}^{\prime}\left(\mathrm{O}^{\prime} \mathrm{Chiu}\right.$ and Vardhanabhuti, manuscript in process). Here the same trend is seen as high charge density WPI- $\lambda \mathrm{C}$ had a higher $\mathrm{G}^{\prime}$ and gel strength than medium charge WPI-IC. The trend was not followed by the WPI-KC samples that have the highest $\mathrm{G}^{\prime}$ and gel strength despite having the lowest charge density. As was discussed in the stability results section $\mathrm{KC}$ at this concentration is able to interact extensively with casein in the solution to form an entangled polymer network that can contribute to increased firmness properties.

The different carrageenans had significantly different aerated gel yield stress $(P=0.0012)$. As yield stress is a measure of foam firmness it is expected to correlate with $\mathrm{G}^{\prime}$ (gel firmness) however, no significant relationship was found $(P=0.44)$. Similar to $G^{\prime}$, yield stress was predicted by regression of gel strength and overrun together with high shear viscosity as a third factor $\left(P=0.048, R^{2}=0.97\right)$ with a higher gel strength and lower overrun resulting in higher yield stress.

Yield Stress $=2119-2.75\left(\right.$ Viscosity at $\left.100 \sec ^{-1}\right)-2.94($ Overrun $)+1.13($ Gel Strength $)$ 


\subsubsection{Lactic Acid Bacteria Gelation}

The primary acidulation agent in this study is glucono- $\delta$-lactone (GDL); it has consistent results with a fast initial $\mathrm{pH}$ decrease. However, the primary application of dairy aerated gels is for whipped yogurts. Milk fermentation with lactic acid bacteria $(L A B)$ is a slower process than with GDL. Although the final $\mathrm{pH}$ reached was the same in 24 hours, fermentation with lactic acid bacteria starts out slowly and then $\mathrm{pH}$ begins to drop at a steady pace. It is known that both the final $\mathrm{pH}$ and the rate of $\mathrm{pH}$ change have a significant effect on gel properties (Jumah and others 2001). Acidification with bacteria also produces several metabolic byproducts such as exopolysaccharides which will effect texture properties (Marle and Zoon 1995; Lucey and others 1998). To confirm that the results on stability from this study could be applied to fermented dairy aerated gels, we repeated the drainage study on samples acidulated with LAB to study how stability is effected by acidulation rate. 


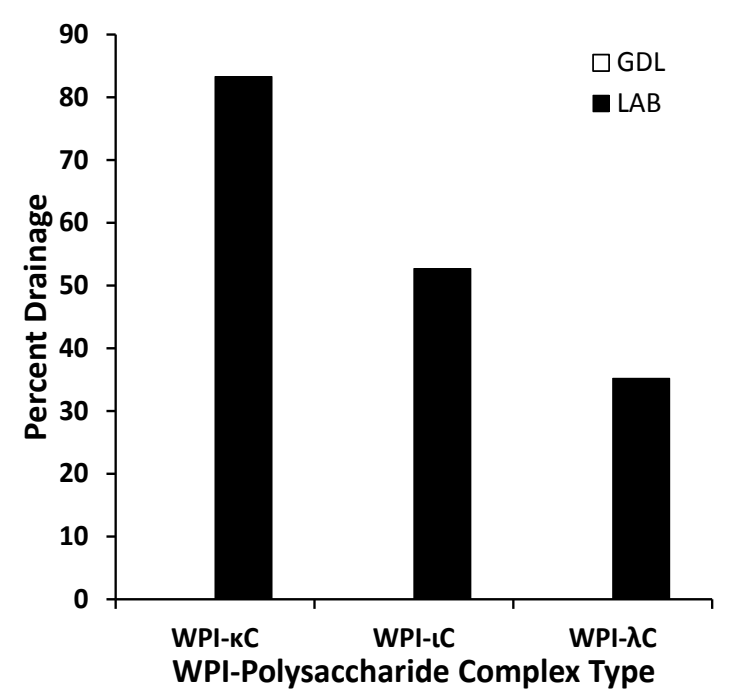

Figure 14 Percent drainage of the aerated gels at polysaccharide concentration $0.126 \%$ with two acidulation methods; GDL (white) and Lactic Acid Bacteria (black)

Drainage results with the two acidulation agents were significantly different $(P<0.0001)$ with the lactic acid bacteria samples having much higher percent drainage than the GDL samples (Figure 14). This concentration of carrageenan was not able to stabilize the aerated gel during the fermentation process. Interestingly, unlike the percent drainage for GDL at lower concentrations, WPI-kC was not the best for stabilizing these samples. Here, the drainage results are in order of charge density with low charge WPI-KC having the least stability at $83.3 \% \pm 7.4$ drainage, followed by WPI-ıC with $52.7 \% \pm 2.8$ drainage and WPI- $\lambda$ C with $35.2 \% \pm 1.5$ drainage. While aerated gels made under these conditions were not able to form stable fermented samples with no drainage, the large improvement made by increasing charge density is promising. It is 
possible that aerated gels with higher concentrations of $\lambda C$, or whipped or fermented under different concentrations could be stable. Further research is needed.

\subsection{Conclusion}

The results of this study confirm that both polysaccharide concentration and electrostatic charge density have an effect on the final properties of aerated gels. It is possible to create stable aerated gels with WPI-polysaccharide complexes by adjusting the polysaccharide type and use level. Increased electrostatic interactions of high charge density polysaccharide complexes with WPI are key to managing overrun and stability. Additionally, the unique molecular structure of heated k-carrageenan also made significant contributions to the aerated gel properties of percent drainage, gel strength, $\mathrm{G}^{\prime}$ and yield stress due to increased bridging interactions with casein micelles. This knowledge can be applied to dairy based gels set by acid or calcium such as yogurt or mousses where aeration can increase their appeal by creating novel textures and reducing calories by volume. 


\section{CHAPTER 5 CONCLUSIONS}

\subsection{Concluding Statements on Aerated Gels}

The results presented in the manuscripts for WPI-Pectin and WPI-Carrageenan present compelling evidence that both polysaccharide concentration and electrostatic charge density have an effect on the final properties of aerated gels. Stable aerated gels cannot be made with heated dairy proteins alone, but they are possible with addition of heated WPI and polysaccharide complexes. Increased electro-static interactions between high charge density polysaccharides and whey proteins when co-heated are key to managing overrun and stability. The textural attributes, yield stress and $\mathrm{G}^{\prime}$, can be predicted using a multiple regression model using gel strength of non-aerated gel and the aerated overrun. Additionally in the carrageenan system, unique bridging interactions between $\mathrm{k}$-carrageenan and casein micelles contributed to aerated gel properties by increasing gel strength, $G^{\prime}$ and yield stress.

\subsection{Overall Benefit and Future Direction}

Stabilization of aerated gels is the first step in being able to apply this research to novel food products. Of the six polysaccharides tested, only the sample containing LM12 pectin at $0.315 \%$ was able to form a stable aerated gel when acidulated with lactic acid bacteria in the conditions used for this study. However, since the underlying factors that influence stabilization are now better understood, the ground work is set for the development of stable, fermented, aerated gels. In addition, future study may investigate the use of calcium and calcium plus iron in developing high protein-high calcium aerated dairy gel products at neutral $\mathrm{pH}$. 


\section{APPENDIX}

Table 5 Additional data for measured aerated gel properties

\begin{tabular}{|c|c|c|c|c|c|}
\hline Type & $\begin{array}{c}\text { Final PS } \\
\text { Concentration }\end{array}$ & Gel strength & $\begin{array}{c}\text { Water Holding } \\
\text { Capacity }\end{array}$ & $\mathrm{pH}$ at 24 hours & $\mathrm{pH}$ at 7 days \\
\hline WPI-LM12 & 0.105 & $228 \pm 4$ & $97.1 \pm 0.3$ & $4.53 \pm 0.01$ & $4.22 \pm 0.01$ \\
\hline WPI-HM D & 0.105 & $204 \pm 1$ & $95.7 \pm 1.32$ & $4.44 \pm 0.01$ & $4.16 \pm 0.0$ \\
\hline WPI-Guar & 0.105 & $231 \pm 2$ & $96.81 \pm 0.02$ & $4.49 \pm 0.01$ & $4.19 \pm 0.01$ \\
\hline WPI-LM12 & 0.210 & $233 \pm 0$ & $97.58 \pm 0.02$ & $4.60 \pm 0.06$ & $4.17 \pm 0.01$ \\
\hline WPI-HM D & 0.210 & $249 \pm 1$ & $96.612 \pm 0.02$ & $4.52 \pm 0.02$ & $4.17 \pm 0.0$ \\
\hline WPI-Guar & 0.210 & $248 \pm 2$ & $95.062 \pm 1.26$ & $4.48 \pm 0.02$ & $4.18 \pm 0.0$ \\
\hline WPI-LM12 & 0.265 & $250 \pm 7$ & $96.92 \pm 0$ & $4.51 \pm 0.01$ & $4.33 \pm 0.03$ \\
\hline WPI-HM D & 0.265 & $265 \pm 4$ & $96.758 \pm 0.03$ & $4.45 \pm 0.04$ & $4.31 \pm .04$ \\
\hline WPI-LM12 & 0.315 & $235 \pm 7$ & $98.14 \pm 0.147$ & $4.54 \pm 0.01$ & $4.23 \pm 0.01$ \\
\hline WPI-HM D & 0.315 & $286 \pm 2$ & $96.619 \pm 0.06$ & $4.42 \pm 0.04$ & $4.18 \pm 0.01$ \\
\hline WPI-Guar & 0.315 & $310 \pm 11$ & $67.33 \pm 1.72$ & $4.48 \pm 0.01$ & $4.20 \pm 0.01$ \\
\hline WPI-кC & 0.042 & $184 \pm 7$ & $96.4 \pm 0.2$ & $4.50 \pm 0.04$ & $4.19 \pm 0.01$ \\
\hline WPI-ıC & 0.042 & $167 \pm 1$ & $96.7 \pm 0.1$ & $4.46 \pm 0.02$ & $4.20 \pm 0.0$ \\
\hline WPI- $\lambda C$ & 0.042 & $158 \pm 6$ & $97.1 \pm 0.3$ & $4.47 \pm 0.02$ & $4.09 \pm 0.01$ \\
\hline WPI-кC & 0.084 & $177 \pm 13$ & $97.1 \pm 0.4$ & $4.49 \pm 0.01$ & $4.18 \pm 0.00$ \\
\hline WPI-ıC & 0.084 & $183 \pm 11$ & $96.6 \pm 0.1$ & $4.45 \pm 0.01$ & $4.20 \pm 0.01$ \\
\hline WPI- $\lambda C$ & 0.084 & $129 \pm 3$ & $95.3 \pm 0.1$ & $4.49 \pm 0.01$ & $4.20 \pm 0.01$ \\
\hline WPI-кC & 0.126 & $199 \pm 1$ & $97.1 \pm 0.2$ & $4.50 \pm 0.01$ & $4.20 \pm 0.01$ \\
\hline WPI-ıC & 0.126 & $108 \pm 1$ & $95.9 \pm 0.1$ & $4.42 \pm 0.02$ & $4.17 \pm 0.01$ \\
\hline WPI- $\lambda C$ & 0.126 & $141 \pm 2$ & $92.1 \pm 0.2$ & $4.49 \pm 0.02$ & $4.19 \pm 0.01$ \\
\hline
\end{tabular}

Values are means $\pm S D$ 

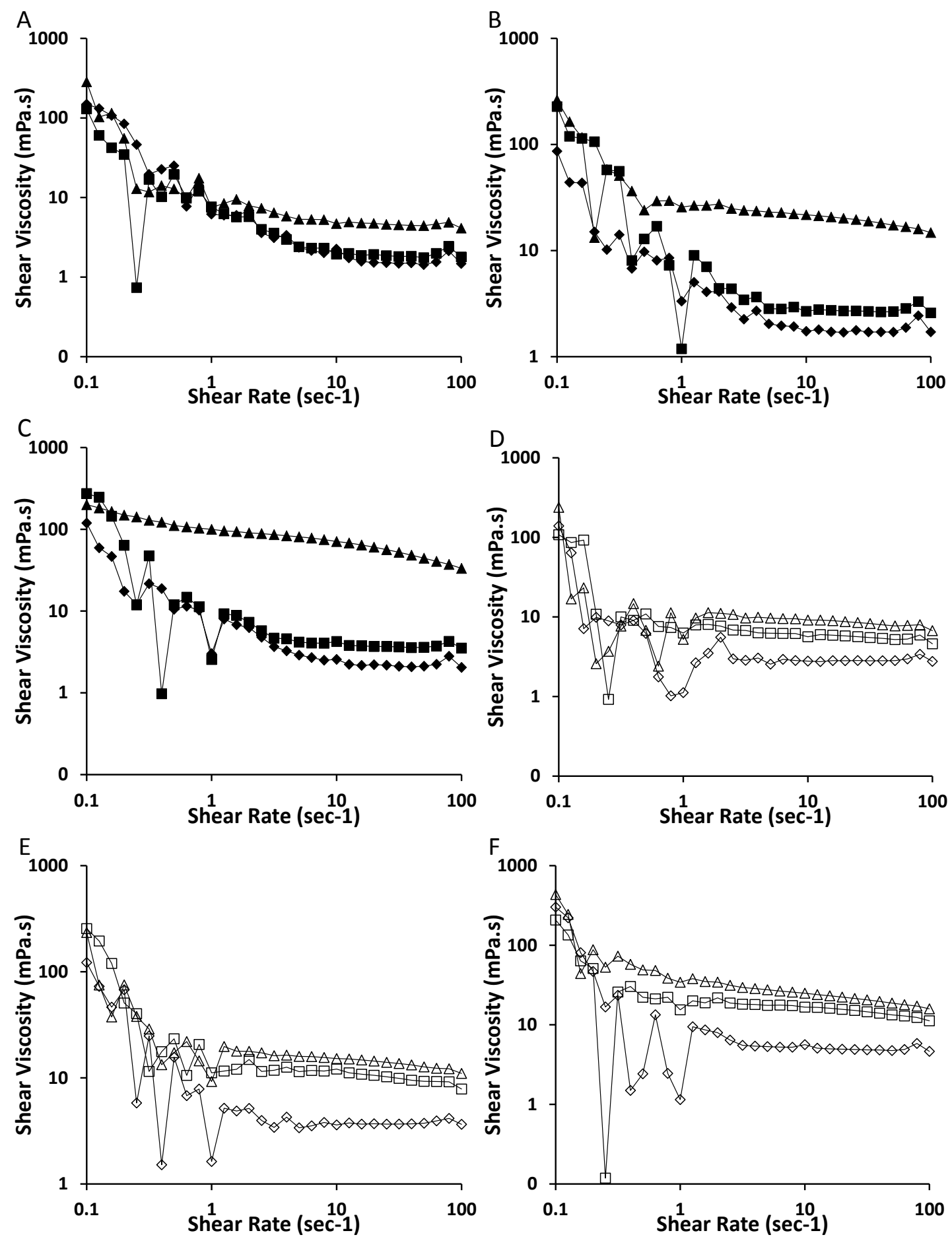

Figure 15 Polysaccharide viscosity response to shear rate A) $0.105 \%, B) 0.21 \%$, C) $0.315 \%, D) 0.042 \%$, E) $0.084 \%, F) 0.126 \%$ \) LM-12 Pectin 1$) H M D$ Pectin $\triangle$ ) Guar Gum $\diamond$ ) k-carrageenan $\triangle$ ) l-carrageenan $\square$ ) $\lambda$-carrageenan 

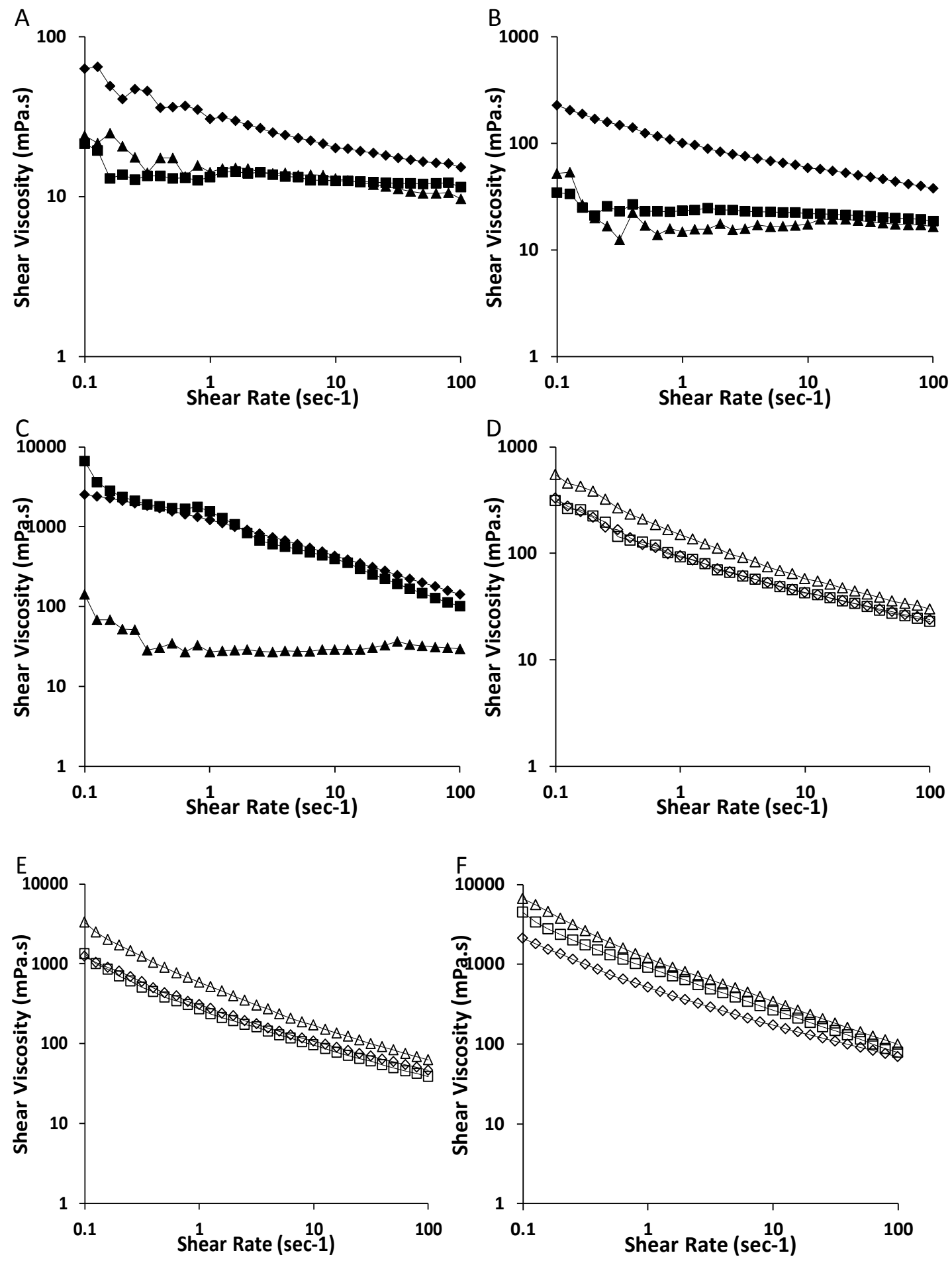

Figure 16 SMP-Complex mixture viscosity response to shear rate A) 0.105\%,

B) $0.21 \%$, C) $0.315 \%, D) 0.042 \%$, E) $0.084 \%, F) 0.126 \%$ ४ LM-12 Pectin —) HM D

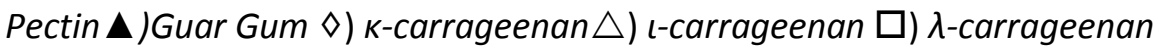




\section{REFERENCES}

Allen KE, Dickinson E, Murray B. 2006. Acidified sodium caseinate emulsion foams containing liquid fat: A comparison with whipped cream. Food Sci Tech. 39:3:225-234

Alting AC, de Jongh HHJ, Visschers RW, Simons J-WFA. 2002. Physical and chemical interactions in cold gelation of food proteins. J Agric Food Chem. 50:16:4682-4689

Bikker JF, Anema SG, Li Y, Hill JP. 2000. Rheological properties of acid gels prepared from heated milk fortified with whey protein mixtures containing the $a, b$ and $c$ variants of $\beta$-lactoglobulin. Int Dairy J. 10:10:723-732

Blijdenstein TBJ, de Groot PWN, Stoyanov SD. 2010. On the link between foam coarsening and surface rheology: Why hydrophobins are so different. Soft Matter. 6:8:1799-1808

Bourriot S, Doublier JL, Garnier C. 1999a. Micellar-casein-kappa-carrageenan mixtures. I. Phase separation and ultrastructure. Carbohydrate Polymers. 40:2:145-157

Bourriot S, Garnier C, Doublier J-L. 1999b. Phase separation, rheology and microstructure of micellar casein-guar gum mixtures. Food Hydrocolloids. 13:1:43-49

Buriti FCA, Castro IA, Saad SMI. 2010. Effects of refrigeration, freezing and replacement of milk fat by inulin and whey protein concentrate on texture profile and sensory acceptance of synbiotic guava mousses. Food Chem 123:4:1190-1197

Campbell GM, Mougeot E. 1999. Creation and characterisation of aerated food products. Trends Food Sci Technol. 10:9:283-296

Cavallieri nLF, Cunha RL. 2009. Cold-set whey protein gels with addition of polysaccharides [electronic resource]. 4:2:94-105

Dalgleish DG. 2011. On the structural models of bovine casein micelles - review and possible improvements. Soft Matter. 7:6:2265-2272

Dalgleish DG, Corredig M. 2012. The structure of the casein micelle of milk and its changes during processing. Annu Rev Food Sci Technol. 3:449-467

Davis JP, Foegeding EA. 2004. Foaming and interfacial properties of polymerized whey protein isolate. J Food Sci. 69:5:C404-C410

de Bont PW, van Kempen GMP, Vreeker R. 2002. Phase separation in milk protein and amylopectin mixtures. Food Hydrocolloids. 16:2:127-138 
de Jong S, van de Velde F. 2007. Charge density of polysaccharide controls microstructure and large deformation properties of mixed gels. Food Hydrocolloids. 21:7:1172-1187

de Kruif CG. 1999. Casein micelle interactions. Int Dairy J. 9:183-188

de Kruif CG, Tuinier R. 2001. Polysaccharide protein interactions. Food Hydrocolloids. $15: 4-6: 555-563$

Del Angel CR, Dalgleish DG. 2006. Structures and some properties of soluble protein complexes formed by the heating of reconstituted skim milk powder. Food Res Int. $39: 4: 472-479$

Donato L, Guyomarc'h F. 2009. Formation and properties of the whey protein/א-casein complexes in heated skim milk - a review. Dairy Sci Technol. 89:1:3-29

Ettelaie R, Khandelwal N, Wilkinson R. 2014. Interactions between casein layers adsorbed on hydrophobic surfaces from self consistent field theory: K-casein versus para-casein. Food Hydrocolloids. 34:236-246

Foegeding EA. 2006. Food biophysics of protein gels: A challenge of nano and macroscopic proportions. Food Biophysics. 1:1:41-50

Foegeding EA, Davis JP, Doucet D, McGuffey MK. 2002. Advances in modifying and understanding whey protein functionality. Trends Food Sci Technol. 13:5:151-159

Gulrez SKH, Al-Assaf S. 2011. Hydrogels: Methods of preparation, characterisation and applications. In: Phillips GO. Progress in molecular and environmental bioengineering from analysis and modeling to technology applications. Winchester, UK: In Tech. 117150

Haedelt J, Beckett ST, Niranjan K. 2007. Bubble-included chocolate: Relating structure with sensory response. J Food Sci. 72:3:E138-E142

Hall WL, Millward DJ, Long SJ, Morgan LM. 2003. Casein and whey exert different effects on plasma amino acid profiles, gastrointestinal hormone secretion and appetite. $\mathrm{Br}$ J Nutr. 89:2:239-248

Heaney RP, Layman DK. 2008. Amount and type of protein influences bone health. Am J Clin Nutr. 87:5:1567S-1570S

Holt C, Horne DS. 1996. The hairy casein micelle: Evolution of the concept and its implications for dairy technology. Neth Milk Dairy J. 50:2:85-111

Horne DS. 1999. Formation and structure of acidified milk gels. Int Dairy J. 9:3-6:261268 
Ji S, Corredig M, Goff HD. 2008. Aggregation of casein micelles and $\kappa$-carrageenan in reconstituted skim milk. Food Hydrocolloids. 22:1:56-64

Jimenez-Junca CA, Gumy JC, Sher A, Niranjan K. 2011. Rheology of milk foams produced by steam injection. J Food Sci. 76:9:E569-E575

Jumah RY, Abu-Jdayil B, Shaker RR. 2001. Effect of type and level of starter culture on the rheological properties of set yogurt during gelation process. Int J Food Properties. $4: 3: 531-544$

Kammesheidt K. 2003. Formulating aerated dairy foods. Dairy Foods. 104:11:38-39

Keogh MK, O'Kennedy BT. 1998. Rheology of stirred yogurt as affected by added milk fat, protein and hydrocolloids. J Food Sci. 63:1:108-112

Kinsella JE, Whitehead DM. 1989. Proteins in whey: Chemical, physical, and functional properties. Adv Food Nutr Res. 33:343-438

Kokini J, Aken Gv. 2006. Discussion session on food emulsions and foams. Food Hydrocolloids. 20:4:438-445

Korhonen H. 2009. Milk-derived bioactive peptides: From science to applications. J Func Foods. 1:2:177-187

Kuhn KR, Cavallieri ÂLF, da Cunha RL. 2010. Cold-set whey protein gels induced by calcium or sodium salt addition. Int J Food Sci Technol. 45:2:348-357

Langendorff V, Cuvelier G, Launay B, Michon C, Parker A, Kruif CGd. 1999. Casein micelle/iota carrageenan interactions in milk: Influence of temperature. Food Hydrocolloids. 13:3:211-218

Langendorff V, Cuvelier G, Launay B, Parker A. 1997. Gelation and flocculation of casein micelle/carrageenan mixtures. Food Hydrocolloids. 11:1:35-40

Langendorff V, Parker A, Kruif CGd, Launay B, Cuvelier G, Michon C. 2000. Effects of carrageenan type on the behaviour of carrageenan/milk mixtures. Food Hydrocolloids. $14: 4: 273-280$

Lau CK, Dickinson E. 2005. Instability and structural change in an aerated system containing egg albumen and invert sugar. Food Hydrocolloids. 19:1:111-121

Lee WJ, Lucey JA. 2006. Impact of gelation conditions and structural breakdown on the physical and sensory properties of stirred yogurts. J Dairy Sci. 89:7:2374-2385 
Lucey JA, Tamehana M, Singh H, Munro PA. 1998. A comparison of the formation, rheological properties and microstructure of acid skim milk gels made with a bacterial culture or glucono- $\delta$-lactone. Food Res Int. 31:2:147-155

Luck PJ, Bray N, Foegeding EA. 2002. Factors determining yield stress and overrun of whey protein foams. J Food Sci. 67:5:1677-1681

Marle MEv, Zoon P. 1995. Permeability and rheological properties of microbially and chemically acidified skim-milk gels. Neth Milk Dairy J. 49:1:47-65

Maroziene A, de Kruif CG. 2000. Interaction of pectin and casein micelles. Food Hydrocolloids. 14:4:391-394

Matia-Merino L, Singh H. 2007. Acid-induced gelation of milk protein concentrates with added pectin: Effect of casein micelle dissociation. Food Hydrocolloids. 21:5-6:765-775

McCrickerd K, Mills T, Yeomans MR, Norton JE, Chambers L, Brunstrom JM. 2012. Subtle changes in the flavour and texture of a drink enhance expectations of satiety [electronic resource]. Appetite 59:2:632-632

McMahon DJ, Du H, McManus WR, Larsen KM. 2009. Microstructural changes in casein supramolecules during acidification of skim milk. J Dairy Sci. 92:12:5854-5867

Mott CL, Hettiarachchy NS, Qi M. 1999. Effect of xanthan gum on enhancing the foaming properties of whey protein isolate. J Amer Oil Chem Soc. 76:11:1383-1386

Osterholt KM, Roe LS, Rolls BJ. 2007. Incorporation of air into a snack food reduces energy intake. 48:3:351-358

Patel MR, Baer RJ, Acharya MR. 2006. Increasing the protein content of ice cream. J Dairy Sci. 89:5:1400-1406

Pernell CW, Daubert CR, Foegeding EA. 2000. Measurement of the yield stress of protein foams by vane rheometry. J Food Sci. 65:1:110-114

Pintor A, Totosaus A. 2012. Ice cream properties affected by lambda-carrageenan or iotacarrageenan interactions with locust bean gum/carboxymethylcellulose mixtures. Int Food Res J. 19:4:1409-1414

Raymundo A, Empis J, Sousa I. 1998. Method to evaluate foaming performance. J Food Eng. 36:4:445-452

Rice BH, Quann EE, Miller GD. 2013. Meeting and exceeding dairy recommendations: Effects of dairy consumption on nutrient intakes and risk of chronic disease. Nutr Rev. 71:209-223 
Schmidt RH, Morris HA. 1984. Gelation properties of milk proteins, soy proteins, and blended protein systems. Food Technol 38:5:85

Schmitt C, Turgeon SL. 2011. Protein/polysaccharide complexes and coacervates in food systems. Adv Colloid Interface Sci. 167:1/2:63-70

Shchipunov YA, Chesnokov AV. 2003. Carrageenan gels in skim milk: Formation and rheological properties. Colloid J 65:1:105-113

Smithers GW. 2008. Whey and whey proteins - from "gutter-to-gold". Int Dairy J. 18:695-704

Snoeren THM, Both P, Jeunink J, Payens TAJ. 1975. Electrostatic interaction between kappa-carrageenan and kappa-casein. Milchwissenschaft. 30:7:393-396

Sodini I, Montella J, Tong PS. 2005. Physical properties of yogurt fortified with various commercial whey protein concentrates. J Sci Food Agric 85:5:853-859

Spagnuolo PA, Dalgleish DG, Goff HD, Morris ER. 2005. Kappa-carrageenan interactions in systems containing casein micelles and polysaccharide stabilizers. Food Hydrocolloids. 19:3:371-377

Tamime AY, Robinson RK, Latrille E. 2001. Yoghurt and other fermented milks. In: Tamime AY and Law BA. Mechanisation and automation in dairy technology. Sheffield, England Boca Raton, FL: Sheffield Academic Press; CRC Press. 152-203

Thaiudom S, Goff HD. 2003. Effect of $\kappa$-carrageenan on milk protein polysaccharide mixtures. Int Dairy J. 13:9:763-771

Thakur RK, Vial C, Djelveh G. 2008. Effect of composition and process parameters on elasticity and solidity of foamed food. Chem Eng Process. 47:3:474-483

Tiwari S, Bhattacharya S. 2011. Aeration of model gels: Rheological characteristics of gellan and agar gels. J Food Eng. 107:1:134-139

Tomczynska-Mleko M. 2013. Structure and stability of ion induced whey protein aerated gels. Czech J Food Sci. 31:3:211-216

TomczyŃSka-Mleko M. 2013. Structure and rheology of aerated whey protein isolate gels obtained at different ph. J Food Nutr Res. 52:1:61-70

Tosi E, Canna L, Lucero H, Ré E. 2007. Foaming properties of sweet whey solutions as modified by thermal treatment. Food Chem 100:2:794-799 
Vardhanabhuti B. 2000. Polymerized whey protein isolates: Characterization, rheological, and gelation properties. [DPhil dissertation] Raleigh, NC: North Carolina State University. 139 p.

Vardhanabhuti B, Khayankan W, Foegeding EA. 2010. Formation of elastic whey protein gels at low ph by acid equilibration. J Food Sci. 75:5:E305-E313

Veldhorst MAB, Nieuwenhuizen AG, Hochstenbach-Waelen A, van Vught AJAH, Westerterp KR, Engelen MPKJ, Brummer R-JM, Deutz NEP, Westerterp-Plantenga MS. 2009. Dose-dependent satiating effect of whey relative to casein or soy. Physiol. Behav. 96:4:675-682

Wang Z. 2013. Foaming properties of whey protein isolate and $\lambda$-carrageenan mixed systems. [MSc thesis] Columbia, MO: Univ. of Missouri. 73 p.

Williams RA, Roe LS, Rolls BJ. 2013. Comparison of three methods to reduce energy density. Effects on daily energy intake. Appetite. 66:75-83

Zhang S, Hsieh F-H, Vardhanabhuti B. 2014. Acid-induced gelation properties of heated whey protein-pectin soluble complex (part i): Effect of initial ph. Food Hydrocolloids 36:76-84

Zhang S, Vardhanabhuti B. 2014. Acid-induced gelation properties of heated whey protein-pectin soluble complex (part ii): Effect of charge density of pectin. Food Hydrocolloids. 39:0:95-103

Zhang S, Zhang Z, Lin M, Vardhanabhuti B. 2012. Raman spectroscopic characterization of structural changes in heated whey protein isolate upon soluble complex formation with pectin at near neutral ph. J Agric Food Chem. 60:48:12029-12035

Zúñiga RN, Aguilera JM. 2008. Aerated food gels: Fabrication and potential applications. Trends Food Sci Technol. 19:4:176-187 